\title{
Mediterranean Sea response to climate change in an ensemble of twenty first century scenarios
}

\author{
Fanny Adloff • Samuel Somot · Florence Sevault • Gabriel Jordà • Roland Aznar • \\ Michel Déqué • Marine Herrmann • Marta Marcos • Clotilde Dubois · Elena Padorno • \\ Enrique Alvarez-Fanjul · Damià Gomis
}

Received: 20 June 2014 / Accepted: 30 January 2015 / Published online: 20 February 2015

(c) The Author(s) 2015. This article is published with open access at Springerlink.com

\begin{abstract}
The Mediterranean climate is expected to become warmer and drier during the twenty-first century. Mediterranean Sea response to climate change could be modulated by the choice of the socio-economic scenario as well as the choice of the boundary conditions mainly the Atlantic hydrography, the river runoff and the atmospheric fluxes. To assess and quantify the sensitivity of the Mediterranean Sea to the twenty-first century climate change, a set of numerical experiments was carried out with the regional ocean model NEMOMED8 set up for the Mediterranean Sea. The model is forced by air-sea fluxes derived from the regional climate model ARPEGE-Climate at a 50-km horizontal resolution. Historical simulations representing the climate of the period 1961-2000 were run to obtain a reference state. From this baseline, various sensitivity experiments were performed for the period 2001-2099, following different socio-economic scenarios based on the Special Report on Emissions Scenarios. For the A2 scenario, the main three boundary forcings (river runoff, near-Atlantic water hydrography and air-sea fluxes) were changed one by one to better identify the role of each forcing in the way the ocean responds to climate change. In two additional simulations (A1B, B1), the scenario is changed, allowing
\end{abstract}

F. Adloff $(\varangle) \cdot$ S. Somot · F. Sevault · M. Déqué · C. Dubois CNRM-GAME, Météo-France, CNRS, Toulouse, France

e-mail: fanny.adloff@meteo.fr

G. Jordà · M. Marcos · D. Gomis

IMEDEA, UIB, Palma de Mallorca, Spain

R. Aznar · E. Padorno $\cdot$ E. Alvarez-Fanjul

Puertos del Estado, Madrid, Spain

M. Herrmann

LEGOS, UMR5566, CNRS-CNES-IRD-Université de Toulouse,

Toulouse, France to quantify the socio-economic uncertainty. Our 6-member scenario simulations display a warming and saltening of the Mediterranean. For the 2070-2099 period compared to 1961-1990, the sea surface temperature anomalies range from +1.73 to $+2.97{ }^{\circ} \mathrm{C}$ and the SSS anomalies spread from +0.48 to +0.89 . In most of the cases, we found that the future Mediterranean thermohaline circulation (MTHC) tends to reach a situation similar to the eastern Mediterranean Transient. However, this response is varying depending on the chosen boundary conditions and socio-economic scenarios. Our numerical experiments suggest that the choice of the near-Atlantic surface water evolution, which is very uncertain in General Circulation Models, has the largest impact on the evolution of the Mediterranean water masses, followed by the choice of the socio-economic scenario. The choice of river runoff and atmospheric forcing both have a smaller impact. The state of the MTHC during the historical period is found to have a large influence on the transfer of surface anomalies toward depth. Besides, subsurface currents are substantially modified in the Ionian Sea and the Balearic region. Finally, the response of thermosteric sea level ranges from +34 to $+49 \mathrm{~cm}$ (2070-2099 vs. 1961-1990), mainly depending on the Atlantic forcing.

Keywords Mediterranean Sea - Climate change .

Boundary conditions

\section{Introduction}

The Mediterranean region has been referenced as one of the most responsive regions to climate change and was defined as a primary "Hot-spot" by Giorgi (2006), based on the results from global climate change projection scenarios. The context of global warming stresses the necessity 
to assess the possible consequences of climate change on this sensitive region which would become warmer and drier (IPCC 2007, 2013). Because local scale processes are acting over the basin and drive the Mediterranean circulation, the use of regional models is required for climate studies over this region ( $\mathrm{Li}$ et al. 2006, 2011).

Confined between Southern Europe, Middle East and North Africa, the Mediterranean is an enclosed basin connected to the wide ocean through the narrow Strait of Gibraltar. The basin has its own thermohaline circulation (called MTHC hereafter) driven by deep and intermediate dense water convection taking place in the Gulf of Lions, the Adriatic, the South Aegean and the North-East Levantine. These processes lead to a short residence time of the water masses compared to the wide ocean $(\approx 100$ years, Malanotte-Rizzoli et al. 2014) and provide oxygen to the deepest part of the water column.

However, the MTHC has varied over time through changes of the surface fluxes acting over the basin. Sediment layers, called sapropels, reflect for instance past circulation states when the MTHC had strongly weakened, preventing the deep ventilation of the basin (e.g. Rohling 1991, 1994). More recently, some circulation changes have been observed in the eastern Mediterranean. This so-called Eastern Mediterranean Transient (EMT) happened in the 1990's and is characterized by a switch of the main location of eastern deep water formation from the Adriatic to the Aegean, and was first reported by Roether et al. (1996). The evolution of the EMT was further analysed by Klein et al. (1999), Lascaratos et al. (1999), Theocharis et al. (1999), Zervakis et al. (2004), Roether et al. (2007). They showed from observational evidences that very dense waters were formed during that period in the Aegean Sea until the basin was filled with dense water, which then overflowed in the Levantine and Ionian basins through the sills of the Cre$\tan$ Arc straits to form Eastern Mediterranean Deep Water (EMDW).

Concerning future projections, the few studies available predict a weakening of the MTHC related to a dominant ocean warming (e.g. Thorpe and Bigg 2000; Somot et al. 2006; Planton et al. 2012). Mediterranean regional climate projections have also been already performed in the frame of the FP5 PRUDENCE project (Christensen et al. 2007) with the A2 scenario in the study by Somot et al. (2006), who found an increase of water loss and a decrease of the heat loss over the basin associated to a warming and salting of Mediterranean waters. A1B scenario has been used for the Mediterranean region in both FP6-CIRCE (Dubois et al. 2012) and FP6-ENSEMBLES (Sanchez-Gomez et al. 2009) projects. Herrmann et al. (2008a) also found a decrease of dense water formation in the shelf of the Gulf of Lions in model projections. Tsimplis et al. (2008) have discussed the different contributors to Mediterranean steric sea level rise based on a single ocean-atmosphere regional model. Later on, Carillo et al. (2012) analysed an ensemble of models and found a large spread on the steric component of the Mediterranean sea level rise which depends on Atlantic boundary conditions. A review of the studies dealing with Mediterranean climate projections is presented in Planton et al. (2012). The regional coupled models intercomparison study by Dubois et al. (2012) presented Mediterranean Sea projections under A1B scenario for 1950-2050 and found a decrease in the heat loss and an increase in water loss over the ocean, which may strongly impact the Mediterranean water masses and the associated MTHC. A recent study by Lazzari et al. (2013) investigated the impact of A1B climate change scenario on the Mediterranean trophic regimes, but their time slice approach presented some limitations compared to the transient approach of the CIRCE project simulations (Gualdi et al. 2013), with smaller SST increase at the end of the twenty-first century compared to other studies. Finally, Herrmann et al. (2014) investigated the impact of climate change on the northwestern Mediterranean Sea pelagic planktonic ecosystem and associated carbon cycle. They found that the seasonal evolution and the interannual variability of the ecosystem components and biogeochemical processes at the end of the twenty-first century would be very similar at the first order to those observed for the end of the twentieth century.

Concerning the sensitivity to the three main boundary conditions (Atlantic hydrography, runoff and surface fluxes), the available studies have mostly focused on the sensitivity to surface fluxes and for the present climate. Harzallah et al. (1993) showed the impact of air-sea fluxes on the Mediterranean water transport and Beuvier et al. (2010) could model the EMT with a realistic air-sea fluxes forcing. Regarding the Atlantic waters, Sannino et al. (2009) and Oddo et al. (2009) investigated its impact on the Mediterranean and a paleoclimatic study by Matthiesen and Haines (2003) modelled the effect of past strong melt water events on the Mediterranean stratification with a hydraulic box model. For the sensitivity to runoff, the impact of the Nile damming alone was investigated in Skliris and Lascaratos (2004) and Skliris et al. (2007) focused on the Mediterranean response to runoff reduction in the post-damming period. Mediterranean paleoclimatic studies have also investigated the response to changes in surface fluxes together with changes in rivers and Atlantic hydrography, with boundary forcings corresponding to past times slices (e.g. Adloff et al. 2011).

Among the studies available, there is still a gap in assessing the uncertainties linked to the change of the Mediterranean ocean behaviour under climate change projections. To our knowledge, the only multi-model study is the FP6CIRCE project ensemble (Gualdi et al. 2013) from which a few surface variables have been studied (Dubois et al. 2012). Furthermore, CIRCE runs ended in 2050 which may be too 
short to distinguish forced changes from the natural variability. In the present study, we try to evaluate some of the uncertainties, namely the choice of socio-economic hypothesis based on the Special Report on Emissions Scenarios (SRES scenarios B1, A1B and A2) and the choice of the boundary forcings (air-sea fluxes, Atlantic ocean hydrography, rivers and Black Sea inputs). We adopt the same modelling approach as followed by Somot et al. (2006), which consisted in using a regional Mediterranean ocean model forced by fluxes extracted from a regional atmospheric model and the Atlantic conditions from a global coupled model. Our 6-member scenario simulation set covers the 1961-2099 period using SRES scenario hypothesis after 2000. In these scenario sensitivity experiments, the boundary conditions (atmospheric fluxes, river runoffs, Atlantic hydrography and socio-economic scenario) are alternatively changed.

We mainly aim at understanding to which extent the choice of the boundary conditions and the choice of the socio-economic scenario drive the model response. Especially, we focus on the water masses and their evolution in the future. We remark that our ensemble does not allow to assess the uncertainty linked to the choice of the regional ocean model which can only be tackled in the frame of a multi-model analysis. However, the use of a single model allows a clearer identification of the impact of different sources of uncertainty not related to regional model biases as all the runs are consistent.

The paper is organized as follows: in Sect. 2 models, forcing and experiments are described. The ocean climate of the 1961-1990 period is presented and compared to observations in Sect. 3. In Sect. 4, we present general aspects of the oceanic components at the end of the twentyfirst century and discuss the sensitivity to the different boundary conditions and to the socio-economic scenarios. We conclude in Sect. 5.

\section{Models, forcings and experiments}

The region ocean model used (NEMOMED8) is the same model as in Beuvier et al. (2010) and Herrmann et al. (2010) but it was forced in hindcast mode in these two studies. In addition, the scenario strategy and the definition of the forcings is very similar to the one applied in Somot et al. (2006).

\subsection{The regional ocean climate model (ORCM)}

The numerical simulations are performed with the NEMOMED8 model (e.g. Beuvier et al. 2010; Herrmann et al. 2010) which is a Mediterranean configuration of the NEMO ocean model (Madec 2008). NEMOMED8 is a state-of-the-art eddy-permitting regional ocean model

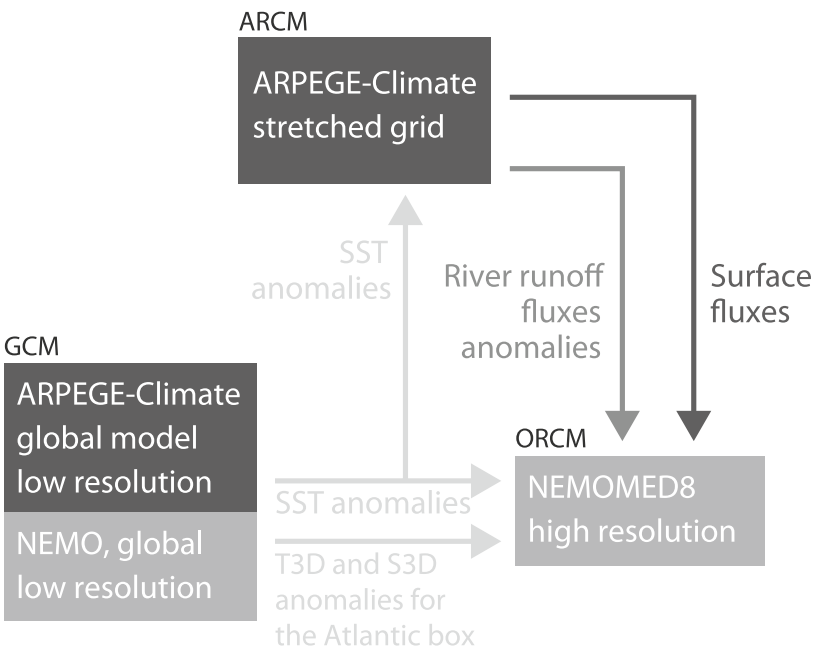

Fig. 1 Sketch of the downscaling strategy explaining the link between the three models (GCM, ARCM and ORCM) used in this study, modified from Somot et al. (2006)

for climate-scale studies. Running the 6-member ensemble (760 years including historical simulations and spin-up) would not have been possible with a higher resolution in a reasonable timing. For the horizontal discretization, an orthogonal curvilinear Arakawa C-grid is used (Arakawa and Lamb 1977), the horizontal resolution is $1 / 8^{\circ} \times 1 / 8^{\circ} \cos (\phi), \phi$ being the latitude $(9-12 \mathrm{~km})$. Thus, the resolution decreases northward. The grid is tilted and stretched at the Gibraltar Strait so that the local resolution is increased up to $6 \mathrm{~km}$. We use a 43-level z-coordinates system, with 10 levels in the upper $100 \mathrm{~m}$. The first layer is centered at $3 \mathrm{~m}$. The time step is $20 \mathrm{~min}$. The partial steps definition of the bottom layer is used, and the surface is parameterized with the free surface configuration.

The horizontal eddy diffusivity is set to $125 \mathrm{~m}^{2} \mathrm{~s}^{-1}$ and the horizontal viscosity coefficient is set to $1 \times 10^{10} \mathrm{~m}^{4} \mathrm{~s}^{-2}$. Convective adjustment is treated by an enhanced vertical coefficient to $50 \mathrm{~m}^{2} \mathrm{~s}^{-1}$ for tracers.

The model grid covers the entire Mediterranean including a small area of the Atlantic, west of Gibraltar up to $11^{\circ} \mathrm{W}$. The bathymetry is based on the ETOPO $5^{\prime} \times 5^{\prime}$ database and the Gibraltar Strait is represented by two grid points.

We use exactly the same settings as in Herrmann et al. (2010) and Beuvier et al. (2010). The largest difference with the study by Somot et al. (2006) is that they used the OPAMED8 regional ocean model and ran only one 140year long simulation.

\subsection{Forcings}

The setup used here is similar to the one used in the study by Somot et al. (2006) (Fig. 1). 


\subsubsection{Surface fluxes and boundary conditions}

At the surface, the Mediterranean regional ocean model is forced by daily air-sea fluxes of heat, momentum and water. The atmospheric surface fluxes are obtained from an atmospheric regional climate model forced by the Sea Surface Temperature (SST) from a general circulation model (Fig. 1). To ensure consistency between the atmospheric heat fluxes and the SST calculated by the regional ocean model, we apply a relaxation term based on the SST from the global model. This term, also considered as a first order coupling, is equal to $-40 \mathrm{~W} \mathrm{~m}^{-2} \mathrm{~K}^{-1}$, homogenously used over the basin. Details concerning the SST relaxation, its significativity and its impact can be found in Sect. 5.2.3 of Somot et al. (2006).

At the western margin, the hydrography of the incoming Atlantic water is relaxed to the 12-month seasonal climatology of temperature and salinity from Reynaud et al. (1998) in the historical simulations, with a Newtonian damping term in the tracer equation. River discharges are explicitly prescribed for the main 33 rivers of the model according to the 12-month climatology derived from the RivDis dataset (Vörösmarty et al. 1998) for the historical period. The Black Sea is not interactive in the NEMOMED8 model, it is treated as an additional river runoff in the Aegean. The 12 values chosen for the Black Sea runoff were taken from the climatology of Stanev et al. (2000) with an annual mean of $6,137 \mathrm{~m}^{3} \mathrm{~s}^{-1}$, a monthly maximum of $10,292 \mathrm{~m}^{3} \mathrm{~s}^{-1}$ in May and a monthly minimum of $-481 \mathrm{~m}^{3} \mathrm{~s}^{-1}$ in August.

To keep the sea level constant in the Mediterranean where evaporation (E) prevails on the water inputs from rivers $(\mathrm{R})$, Black Sea input $(\mathrm{B})$ and precipitation $(\mathrm{P})$, we add the E-P-R-B value averaged over the Mediterranean to the Atlantic part of the grid at each time step, with an imposed slope descending from the western boundary at $11^{\circ} \mathrm{W}$ to $7.5^{\circ} \mathrm{W}$.

To prevent a salinity drift in present climate and to avoid the use of a salinity damping, we choose to correct the E-P-R-B flux from the atmospheric regional climate model, on a monthly basis, through the addition of a corrective term (12 values) as it has been done in Beuvier et al. (2010). This value is fitted to obtain a balanced freshwater budget. Using a correction instead of a relaxation allows not to alter the SSS spatio-temporal variability. This value differs according to the version of the atmospheric regional climate model used and will be specified later on. This correction is made to obtain a stable ocean state for the present climate in the model whose water fluxes are not good enough to achieve this stability without correction. The correction is small with respect to the E-P-R budget $(<10 \%)$ and is constant in time.

\subsubsection{The general circulation model (GCM)}

The global coupled model used in our study is the CNRMCM developed at the Centre National de Recherches Météorologiques (CNRM, Toulouse, France). CNRM-CM results from the coupling of the OPA or NEMO ocean model (Madec et al. 1998; Madec 2008) and the ARPEGEClimate atmosphere model (Déqué et al. 1994) with the OASIS3 coupler (Valcke 2013). To test different sets of boundary conditions, we are using two different versions of CNRM-CM: GCM2 (Royer et al. 2002) and GCM3 (Salas y Mélia et al. 2005), the latest being used for CMIP3 and the IPCC-AR4. The global model CNRM-CM provides the SST information to the regional atmospheric model ARPEGE-Climate, as well as the 3D hydrographic information for the Atlantic boundary in NEMOMED8, in the case of scenario projections (details in Sect. 2.4). The main differences in GCM3 compared to GCM2 are the finer vertical resolution of the atmospheric component and the development of the sea-ice component. It is important to notice that there are not enough elements to assess if one of those simulations is more realistic. Here we consider these two simulations as plausible.

\subsubsection{The atmospheric regional climate model (ARCM)}

The ARPEGE grid can be stretched over an area of interest (Déqué and Piedelièvre 1995). Here, we use a version with an equivalent linear spectral truncation TL159 and a stretching factor equal to 2.5 , with a pole located in the Tyrrhenian Sea. The resolution is thus about $50 \mathrm{~km}$ over the Mediterranean Basin. The time step is $22.5 \mathrm{~min}$.

ARPEGE-Climate is only forced by varying solar constant, sea surface temperature (SST), greenhouse gases concentrations and aerosols concentrations (see for example Gibelin and Déqué 2003; Somot et al. 2006; Déqué 2007), so the historical simulations do not follow the past atmospheric chronology. The versions 3 (RCM3) and 4 (RCM4) of the ARPEGE-Climate model are used in the present study, noting that both versions share most of the physical parameterization schemes, close to the one described in Gibelin and Déqué (2003). The atmosphere model uses the observed greenhouse gases and aerosols concentrations from 1950 up to year 2000 for the historical runs. From 2001 up to 2100 it uses concentrations based on the SRES (B1, A1B and A2). For the SST, we use SST coming from global climate model (GCM) simulations (twentith century historical runs and twenty-first century scenarios) as detailed in Sect. 2.2.2. Before use, the GCM SST bias is corrected as in Somot et al. (2006): the mean seasonal cycle (12 values) of the model SST bias with respect to ERA40 SSTs (Uppala et al. 2005) is computed over the period 1958-2000 on the GCM grid. 
Table 1 Summary of the experiments

\begin{tabular}{llllll}
\hline Experiment & Scenario GH gases / aerosols & Time period & Surface fluxes & & Rivers and Black Sea \\
\hline HIS & obs & $1961-1999$ & RCM3 & clim & clim \\
HIS-F & obs & $1961-2000$ & RCM4 & clim & clim \\
A2 & A2 & $2000-2099$ & RCM3 & RCM3 ano & GCM2 ano \\
A2-F & A2 & $2001-2099$ & RCM4 & RCM3 ano & GCM2 ano \\
A2-RF & A2 & $2001-2099$ & RCM4 & RCM4 ano & GCM2 ano \\
A2-ARF & A2 & $2001-2099$ & RCM4 & RCM4 ano & GCM3 ano \\
A1B-ARF & A1B & $2001-2099$ & RCM4 & RCM4 ano & GCM3 ano \\
B1-ARF & B1 & $2001-2099$ & RCM4 & RCM4 ano & GCM3 ano
\end{tabular}

The model versions used to obtain the boundary forcings, surface fluxes $(\mathrm{F})$, river runoff $(\mathrm{R})$ and Atlantic hydrography $(\mathrm{A})$, are detailed for each simulation. "Ano" states for anomaly

Table 2 Components of the freshwater budget averaged over the Mediterranean: $\mathrm{P}$ for precipitation, R for river, E for evaporation, B for Black Sea net inflow and GWT for Gibraltar water transport (net, outflow and inflow)

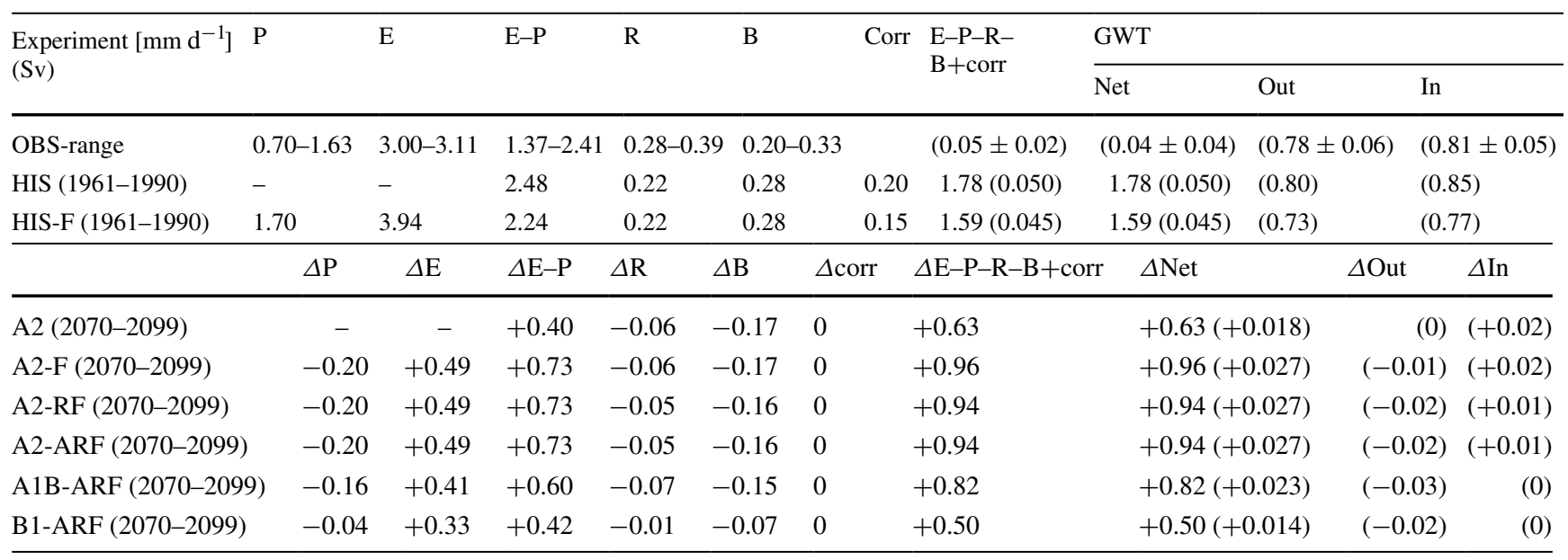

The unit is $\mathrm{mm} \mathrm{d}^{-1}$, except for values in brackets which are in Sv. The observations range comes from the data-gathering by Sanchez-Gomez et al. (2011) for the P, E and E-P terms ; from Ludwig et al. (2009) and Struglia et al. (2004) for R ; from Lacombe and Tchernia (1972); Stanev et al. (2000) and Kourafalou and Barbopoulos (2003) for B ; from Soto-Navarro et al. (2010) and Soto-Navarro et al. (2014) for GWT and E-P$\mathrm{R}-\mathrm{B}$. For the simulations HIS and A2, the $\mathrm{P}$ and $\mathrm{E}$ terms were not separated as single model outputs, they are thus not available

This seasonal cycle of bias is then subtracted to all years of the historical (1961-2000) and scenario (2001-2099) simulations. The SST bias correction remains constant in time.

\subsection{Simulations set}

In this study, we present a family of 8 runs (Table 1): 6 scenario sensitivity simulations and 2 historical simulations. When the surface fluxes (F) and/or the river runoff (R) come from the newest version of ARPEGE-Climate (RCM4), the simulation name contains a " $\mathrm{F}^{\text {" }}$ and / or a "R" in its acronym. When the Atlantic hydrography (A) comes from the newest version of CNRM-CM (GCM3), the simulation name contains an "A" in its acronym. If not, then the lateral boundary conditions come from older model versions (RCM3 and GCM2). In the NEMOMED8 simulations where the atmospheric forcing is derived from RCM3, the freshwater correction term is $0.20 \mathrm{~mm} \mathrm{~d}^{-1}$, whereas it is $0.15 \mathrm{~mm} \mathrm{~d}^{-1}$ with RCM4 (Table 2).

In the scenario sensitivity experiments, the origin of the boundary conditions F, R and A are alternatively changed. These different combinations of forcings allow to analyse the sensitivity of the future evolution of Mediterranean water masses to boundary conditions. The sensitivity to river runoff will be assessed through the comparison of A2-F and A2-RF, the sensitivity to the Atlantic hydrography can be analysed by comparing A2-RF and A2-ARF, and the sensitivity to surface fluxes is evaluated confronting A2 and A2-F. Besides, the sensitivity to the choice of the scenario can also be assessed through the comparison of A2-ARF, A1B-ARF and B1-ARF.

HIS is the baseline of the scenario simulation A2, both get surface fluxes from the old version RCM3. The 
Fig. 2 Representation of the Mediterranean sub-basins and the Atlantic buffer zone in the NEMOMED8 ocean model. ATL (Atlantic box), WMED (Western Mediterranean), LION (Gulf of Lions), ADRI (Adriatic), ION (Ionian), LEV (Levantine), AEG (Aegean)

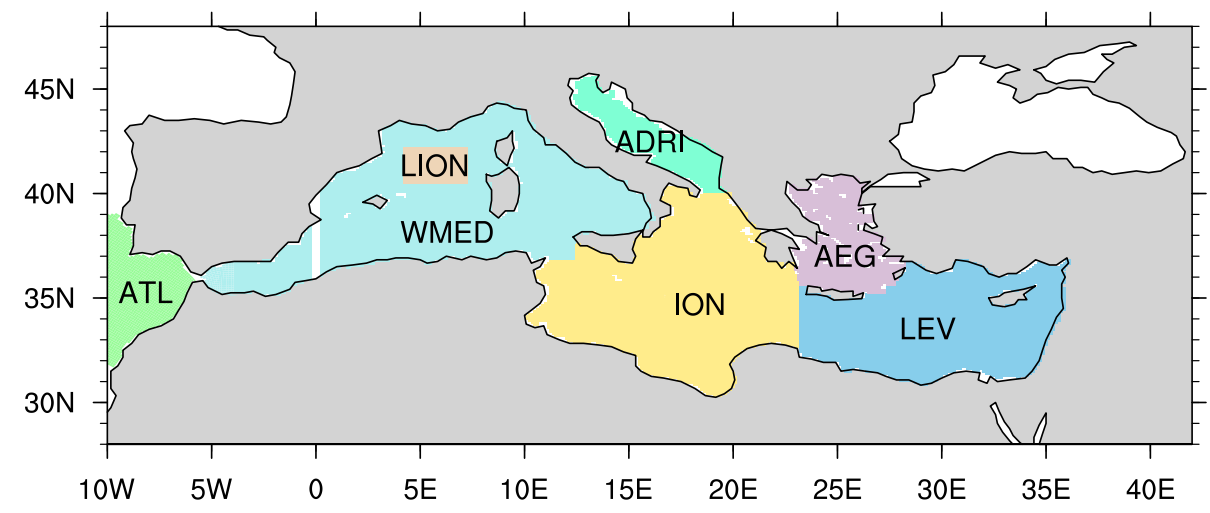

historical simulation HIS-F uses the surface fluxes from the newer version RCM4 and is the baseline of the scenario simulations A2-F, A2-RF, A2-ARF, A1B-ARF and B1-ARF.

\subsection{Rivers and Atlantic forcing in scenarios}

For the projections, the regional ocean scenario simulations A2-F, A2-RF, A2-ARF, B1-ARF and A1B-ARF (20012099 period) use the T/S anomaly field from the global model (GCM2 or GCM3) for the prescription of Atlantic hydrographic conditions at the western margin (Fig. 1). We compute the anomalies by subtracting the mean of the 1961-2000 period from the scenario simulation results. The anomaly profile is then added to the Reynaud et al. (1998) climatology used in the historical simulations. Concerning the rivers, we proceed in the same way as for the Atlantic by adding the runoff anomalies from the stretched ARPEGE-Climate model to the rivers climatology. It must be noted that ARPEGE-Climat includes the land-surface scheme ISBA which collects the runoffs.

In the A2 simulation, we proceed as Somot et al. (2006) using 10-year filtered anomalies for both rivers and Atlantic boundary forcings. This may induce very small changes.

\subsection{Initial conditions, spin-up and runs}

In the Mediterranean basin, we start the simulations from an initial hydrographic state given by the MEDATLASII climatology (MEDAR-Group 2002) for the month of August. In the Atlantic part of the model, we start from the hydrography given by Reynaud et al. (1998). We first performed a 5-year spin-up with a 3-D restoring to the climatologies, so that the velocities can start. Then, we run the model for 15 more years for the historical period 1960-1974. We are aware of the relatively too short spin-up period, but the hydrography of the surface and intermediate waters becomes stable enough after these 20 years with the help of the water flux correction (see
Sect. 2.2.1). The stability of the historical simulations is analysed in Sect. 3.4.

After this spin-up, the historical simulations HIS and HIS-F start from 1961 until 2000. The scenario simulations start from 2001 to 2099 from HIS-F, except for A2 which starts in year 2000 from HIS. To make this current study comparable to former studies and to maximize the signalto-noise ratio and minimize the uncertainty due to natural variability, we compare the period 2070-2099 for the scenario simulations with the period 1961-1990 of the historical simulations. These both time slices are commonly used to evaluate present and future climates.

We are aware that the use of a single model may be a limitation but it also allows a clearer identification of the impact of the different uncertainty sources. The uncertainty related to the choice of the GCM or ARCM or ORCM has been partially tackled in CIRCE (Gualdi et al. 2013; Dubois et al. 2012) and a larger multi-model exercice is currently being organised under the umbrella of the Hymex, MedCORDEX and Med-CLIVAR programs.

\section{Evaluation of the ocean climate for the 1961-1990 period}

In order to assess the ability of the model to reproduce the ocean climate of past decades, we compare the results from the simulations HIS and HIS-F with observations. Keeping in mind that the historical simulations do not follow the real chronology of past atmospheric state, we evaluate the simulations in terms of the mean state. For conciseness reasons, the model evaluation can not be exhaustive, we thus focus on the main equilibrium diagnostics and on the thermohaline circulation. The reader can find an extensive evaluation of NEMOMED8 in hindcast mode in Beuvier et al. (2010), Herrmann et al. (2010), Sevault et al. (2009). Figure 2 represents the spatial coverage of different sub-basins of the Mediterranean and the Atlantic buffer zone in the NEMOMED8 grid. These are used for sub-basin averaging in the following. 
Table 3 Surface heat loss (SHL), heat content trend $(\triangle H C)$ and net heat and salt transport at the Gibraltar Strait (GHT and GST) averaged over the Mediterranean basin

\begin{tabular}{|c|c|c|c|c|c|c|c|c|}
\hline \multirow[t]{2}{*}{ Experiment } & \multirow[t]{2}{*}{$\operatorname{SHL}\left(\mathrm{W} \mathrm{m}^{-2}\right)$} & \multirow[t]{2}{*}{$\Delta H C\left(\mathrm{~W} \mathrm{~m}^{-2}\right)$} & \multicolumn{3}{|c|}{$\operatorname{GHT}\left(\mathrm{W} \mathrm{m}^{-2}\right)$} & \multicolumn{3}{|c|}{$\operatorname{GST}\left(10^{8} \mathrm{~g} \mathrm{~s}^{-1}\right)$} \\
\hline & & & Net & Out & In & Net & Out & In \\
\hline OBS-range & $1 \pm 8$ & 0.09 & {$[3-10]$} & & & & & \\
\hline HIS (1961-1990) & 6 & 0 & 6 & 17 & 23 & 2 & 313 & 315 \\
\hline \multirow[t]{2}{*}{ HIS-F (1961-1990) } & 4 & 1 & 5 & 16 & 21 & 1 & 284 & 285 \\
\hline & $\Delta$ & $\Delta$ & & $\Delta$ & & & $\Delta$ & \\
\hline A2 (2070-2099) & -2.5 & +3.5 & +1 & +2 & +3 & +5 & +4 & +9 \\
\hline A2-F (2070-2099) & -2 & +3 & +1 & +2 & +3 & +8 & 0 & +8 \\
\hline A2-RF (2070-2099) & -3 & +3 & 0 & +2 & +2 & +9 & -2 & +7 \\
\hline A2-ARF (2070-2099) & -2 & +4 & +2 & +1 & +3 & +12 & -4 & +8 \\
\hline A1B-ARF (2070-2099) & -1 & +3 & +2 & +1 & +3 & +11 & -5 & +6 \\
\hline B1-ARF (2070-2099) & -1 & +2 & +1 & +1 & +2 & +8 & -5 & +3 \\
\hline
\end{tabular}

The observations range comes from the data-gathering by Sanchez-Gomez et al. (2011) for SHL; from the data of MEDATLAS-II (1945-2002 period MEDAR-Group 2002) for $\triangle H C$; from different in situ measurements summarized in Dubois et al. (2012) for GHT. Anomalies (20702099 vs. 1961-1990) are represented for the scenario simulations

\subsection{Surface fluxes}

Table 2 compiles the mean value of the freshwater budget components for the simulations and for observational data. The precipitation term of the atmospheric forcing is rather high in comparison with observations (see Sanchez-Gomez et al. 2011), however the observed precipitation over the Mediterranean Sea is very uncertain, especially near the coast where the different observational dataset strongly disagree. Concerning the evaporation, the mean value of our forcing fields is high, but this correlates well with the high precipitation rate displayed by the atmospheric model. ARPEGE-Climat is known to have an enhanced hydrological cycle as analysed in Sanchez-Gomez et al. (2011) and Dubois et al. (2012). This explains the overestimation of $P$ and $\mathrm{E}$.

Mean river runoff is weak, but the "runoff" from the Black Sea into the Mediterranean falls into the observations range. The "E-P-R-B + corr" value is strictly compensated by the net water inflow through the Strait of Gibraltar due to model setup (see Sect. 2.2.1). The net water flux, the inflow and the outflow through Gibraltar are relatively consistent with the range of observations recorded by SotoNavarro et al. (2010, 2014). Soto-Navarro et al. (2014) have also recently shown that NEMOMED8 shows good results in representing the volume transport at the Gibraltar Strait despite a resolution which is not sufficient to resolve the small scale processes taking place in the narrow strait. In any case, it must be kept in mind that mixing across the strait is underestimated in Mediterranean climate models due to low resolution and the absence of tidal forcing (Naranjo et al. 2014). Unfortunately, running regional climate models with enough resolution to solve the hydraulic regimes in the Strait $(<500 \mathrm{~m}$; Sannino et al. 2014) is currently not feasible.

In stable climate, it is assumed that the net heat loss at the surface is compensated by the net heat gain at Gibraltar. Table 3 displays that both historical simulations have a relatively consistent balance between these two terms whose little difference is explained by the full basin heat content derive $(\triangle \mathrm{HC})$ between the year 1961 and the year 1990. The net surface heat fluxes averaged over the basin are consistent with the observations (Table 3) and the net heat transport at Gibraltar is also within the range of observed values.

\subsection{Heat, salt and density contents}

For the historical period 1961-1990, both simulations HIS and HIS-F are relatively close to the observations as seen in Table 4. Concerning the salinity, the vertical gradient is slightly enhanced in both simulations with water fresher than the obervations in the upper layer $0-150 \mathrm{~m}$ and saltier in the deepest layer 600-bottom. The salinity averaged over the full water column is in agreement with the observed one. For the potential temperature, HIS is generally too cold, especially in the upper layer $0-150 \mathrm{~m}$ where the discrepancy reaches almost $1{ }^{\circ} \mathrm{C}$. HIS-F is much closer to the observations, the temperature averaged over the full basin is around $0.1{ }^{\circ} \mathrm{C}$ warmer, however the upper part of the water column is around $0.1{ }^{\circ} \mathrm{C}$ colder. The temperature gradient is thus weaker than in the observations. Despite the mentioned discrepancies, the simulation of the heat and salt contents has been well improved since the study by Somot et al. (2006) or Carillo et al. (2012), especially for deep layers. 
Table 4 Heat and salt content averaged over the Mediterranean for different layers of the water column

\begin{tabular}{|c|c|c|c|c|c|c|c|c|c|c|}
\hline \multirow[t]{2}{*}{ Dataset } & \multicolumn{5}{|c|}{ Salinity } & \multicolumn{5}{|c|}{ Temperature $\left({ }^{\circ} \mathrm{C}\right)$} \\
\hline & SSS & 0-bot & $0-150$ & $150-600$ & 600-bot & SST & 0 -bot & $0-150$ & $150-600$ & 600-bot \\
\hline MEDATLAS-II (1961-1990) & 38.11 & 38.61 & 38.35 & 38.71 & 38.62 & 19.7 & 13.69 & 16.31 & 14.09 & 13.24 \\
\hline Marullo (1985-2007) & & & & & & 19.83 & & & & \\
\hline EN3 (1961-1990) & 38.21 & 38.62 & 38.40 & 38.72 & 38.61 & 19.8 & 13.65 & 16.26 & 14.07 & 13.24 \\
\hline HIS & 38.09 & 38.65 & 38.23 & 38.70 & 38.68 & 18.69 & 13.51 & 15.25 & 13.58 & 13.27 \\
\hline HIS-F & 38.09 & 38.62 & 38.23 & 38.75 & 38.63 & 19.28 & 13.77 & 16.18 & 14.27 & 13.33 \\
\hline $\mathrm{A} 2$ & +0.48 & +0.33 & +0.41 & +0.41 & +0.31 & +2.53 & +0.97 & +2.06 & +1.20 & +0.76 \\
\hline A2-F & +0.69 & +0.33 & +0.58 & +0.47 & +0.26 & +2.97 & +1.04 & +2.30 & +1.36 & +0.79 \\
\hline A2-RF & +0.64 & +0.28 & +0.55 & +0.42 & +0.22 & +2.97 & +0.93 & +2.29 & +1.26 & +0.68 \\
\hline A2-ARF & +0.89 & +0.44 & +0.74 & +0.44 & +0.41 & +2.97 & +1.23 & +2.23 & +1.08 & +1.14 \\
\hline A1B-ARF & +0.85 & +0.52 & +0.72 & +0.47 & +0.51 & +2.46 & +1.35 & +1.80 & +2.00 & +1.38 \\
\hline B1-ARF & +0.70 & +0.43 & +0.60 & +0.39 & +0.42 & +1.73 & +1.09 & +1.29 & +1.79 & +1.15 \\
\hline
\end{tabular}

A comparison of these quantities is made between the observational datasets MEDATLAS-II (MEDAR-Group 2002; Marullo et al. 2011 and from EN3 Ingleby and Huddleston 2007) and both historical simulations HIS and HIS-F, for the period 1961-1990. The difference between modelled quantities in scenario simulations (2070-2099) and the respective historical simulation (1961-1990) is displayed

Table 5 Density averaged over the Mediterranean for different layers of the water column (SSD stands for Sea Surface Density) and stratification index $(I S)$ averaged over the Mediterranean (MED), the western basin (MEDW) and the eastern basin without Aegean and Adriatic (MEDE)

\begin{tabular}{|c|c|c|c|c|c|c|c|c|}
\hline \multirow[t]{2}{*}{ Dataset } & \multicolumn{5}{|c|}{ Potential density $\left(\mathrm{kg} \mathrm{m}^{-3}\right)$} & \multicolumn{3}{|c|}{ IS $\left(\mathrm{m}^{2} \mathrm{~s}^{-2}\right)$} \\
\hline & SSD & 0-bot & $0-150$ & $150-600$ & 600-bot & MED & MEDW & MEDE \\
\hline MEDATLAS-II & 27.31 & 29.03 & 28.17 & 29.05 & 29.13 & 1.70 & 1.90 & 1.95 \\
\hline HIS & 27.44 & 29.10 & 28.31 & 29.16 & 29.19 & 1.37 & 1.82 & 1.39 \\
\hline HIS-F & 27.23 & 29.02 & 28.10 & 29.04 & 29.13 & 1.75 & 2.36 & 1.75 \\
\hline $\mathrm{A} 2$ & -0.26 & +0.05 & -0.17 & -0.04 & +0.07 & +0.47 & +0.54 & +0.53 \\
\hline $\mathrm{A} 2-\mathrm{F}$ & -0.25 & +0.02 & -0.11 & +0.06 & +0.03 & +0.22 & +0.36 & +0.19 \\
\hline $\mathrm{A} 2-\mathrm{RF}$ & -0.26 & +0.01 & -0.14 & +0.04 & +0.02 & +0.26 & +0.37 & +0.25 \\
\hline A2-ARF & -0.10 & +0.07 & n.s. & +0.10 & +0.07 & +0.04 & +0.09 & +0.02 \\
\hline A1B-ARF & 0 & +0.11 & +0.10 & +0.14 & +0.10 & -0.07 & -0.03 & -0.11 \\
\hline B1-ARF & +0.10 & +0.09 & +0.15 & +0.13 & +0.08 & -0.20 & -0.18 & -0.26 \\
\hline
\end{tabular}

A comparison of these quantities is made between the observational dataset MEDATLAS-II (MEDAR-Group 2002) for the period 1945-2002 and both historical simulations, HIS and HIS-F, for the period 1961-1990. The difference between modelled quantities in scenario simulations (2070-2099) and the respective historical simulation (1961-1990) is displayed. The statistical significance is estimated using a $t$ test, "n.s." means that the value is not significant

Table 5 displays the resulting mean density averaged over the basin for different layers of the water column. The cold and salty biases of HIS make this simulation denser than the MEDATLAS-II observations. HIS-F has an averaged density which is close to MEDATLAS-II. If we look at different layers, it is noticed that the density gradient between the $150-600 \mathrm{~m}$ layer and the 600-bottom layer is very small in HIS with a density difference of $0.03 \mathrm{~kg} \mathrm{~m}^{-3}$ compared to MEDATLAS-II $\left(0.08 \mathrm{~kg} \mathrm{~m}^{-3}\right)$, HIS-F is closer with a value of $0.09 \mathrm{~kg} \mathrm{~m}^{-3}$. Hence, we analyse the robustness of the vertical stratification with a stratification index in the next subsection.

\subsection{Vertical stratification}

To assess how good the historical simulations, HIS and HIS$\mathrm{F}$, represent the climate of last decades, we analyse the vertical stratification of the water column calculating an Index of Stratification (IS) (in $\mathrm{m}^{2} \mathrm{~s}^{-2}$, see Beuvier et al. 2010; Herrmann et al. 2008b; Lascaratos 1993). This index has been used in previous studies to investigate the preconditioning of the convection by looking at the changes in the vertical stratification. It corresponds to the loss of buoyancy which must be provided to the stratified water to induce a convection event up to the depth $h$. The lower the index, the more 
Fig. 3 Index of stratification $\left(I S\right.$, in $\left.\mathrm{m}^{2} \mathrm{~s}^{-2}\right)$ calculated over the water column up to $1,000 \mathrm{~m}$ depth. The MEDATLAS-II climatology (1945-2002) is represented in the upper plot. Anomalies of HIS and HIS-F averaged over the 1961-1990 period (vs. MEDATLAS-II) are represented in the middle and bottom plots
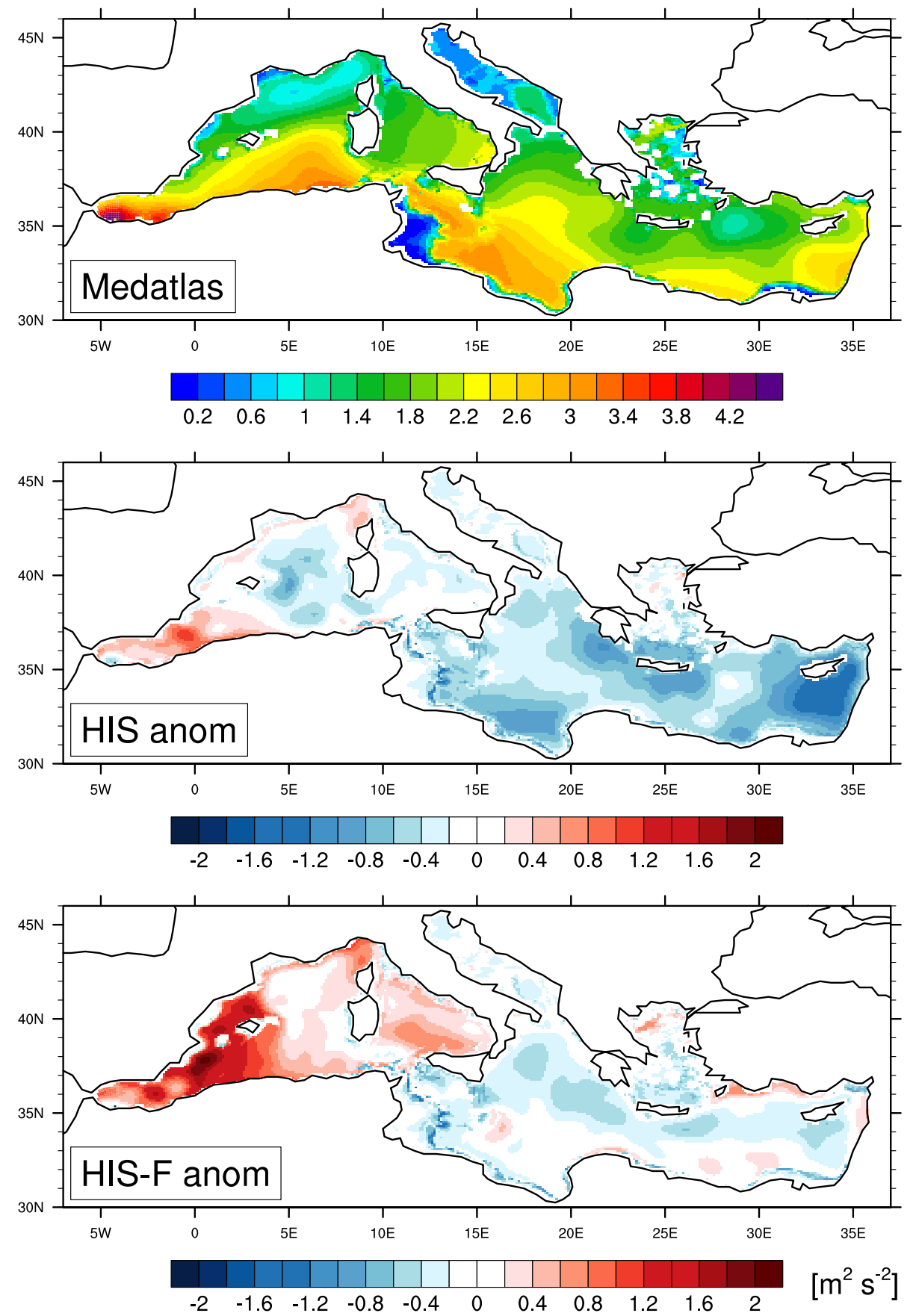

likely is the convection to occur. In our study, we chose to set the maximum depth $h$ to the bottom or to $1,000 \mathrm{~m}$ when the depth is larger than $1,000 \mathrm{~m}$. IS is calculated at each model grid point $(x, y)$ using the following formula:

$I S(x, y, h)=\int_{0}^{h(x, y)} N^{2}(x, y, z) z \mathrm{~d} z$,

where $z$ is the depth and $N$ is the local Brunt-Väisälä frequency: $N^{2}=\frac{g}{\rho} \frac{\partial \rho}{\partial z}$.

Figure 3 represents $I S$ of the MEDATLAS-II climatology and the $I S$ anomalies of HIS and HIS-F with respect to the climatology. We found HIS-F to present a more realistic vertical stratification than HIS on a global average (Table 5). However, focusing on the western basin, HIS-F is too vertically stratified, especially in the Alboran and Balearic regions (Fig. 3) and HIS performs better, despite a slight lack of vertical stratification in the Gulf of Lions region. The positive biases of HIS-F in the Alboran region could be related to a deficient mixing of the surface Atlantic water passing through the Strait of Gibraltar, which may create a strong surface stratification. In the eastern basin, HIS -F is much closer to the MEDATLAS-II vertical stratification 
than HIS, the latter presents strong negative biases reflecting the low vertical stratification in disagreement with MEDATLAS-II (Fig. 3).

\subsection{Stability of historical simulations}

The achievement of water masses stability in the ocean model is the biggest pre-requisite before starting scenario simulations to make sure that future water masses evolution is exclusively connected to climate change. For computertime reasons, we did not perform a long spin-up before starting the historical simulations (see Sect. 2.5) neither a control simulation. However, despite a short spin-up, the model trend remains acceptable. Table 3 displays the trend of the Mediterranean heat content $\triangle H C$ in $\mathrm{W} \mathrm{m}^{-2}$. The weak trend modelled for the historical period 19611990 is mainly related with a temperature increase occuring during the 1980's. The trend can also be expressed in ${ }^{\circ} \mathrm{Cy}^{-1}$ which gives the values of $0.001^{\circ} \mathrm{Cy}^{-1}$ in HIS and $0.002{ }^{\circ} \mathrm{Cy}^{-1}$ in HIS-F. These trends are three orders of magnitude lower than the expected trend related to climate change (see Somot et al. (2006) and Sect. 4.2).

\subsection{Surface circulation}

The general dynamic feature of the Mediterranean Sea for the 1961-1990 period is illustrated in the Fig. 4 by the nearsurface currents field at $34 \mathrm{~m}$ depth. In the model, lower density Atlantic waters enter at Gibraltar, are trapped into
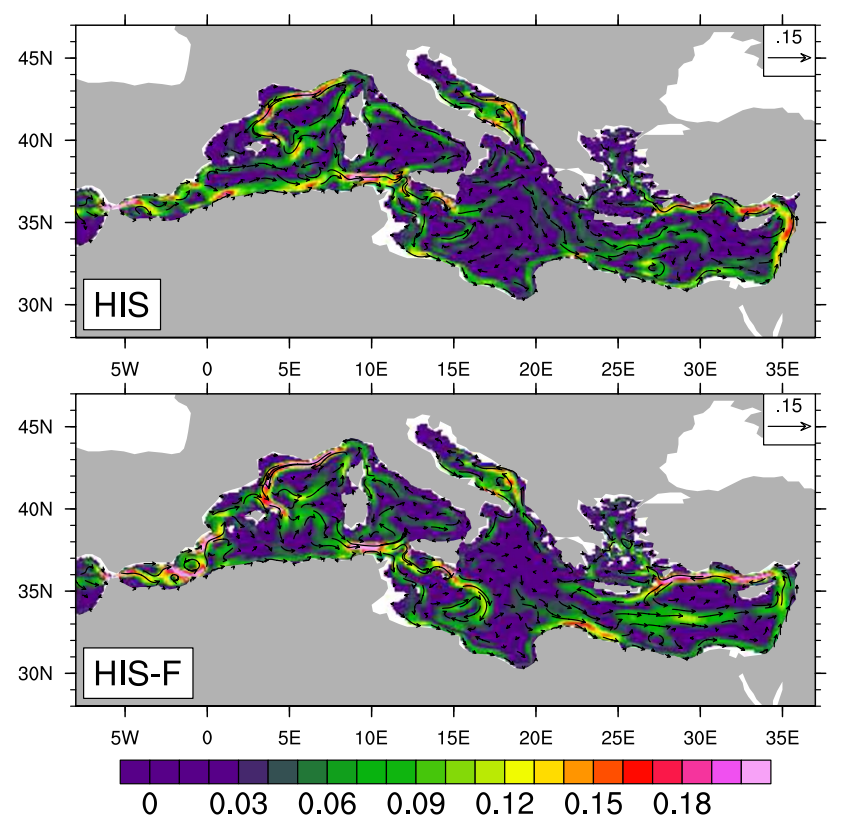

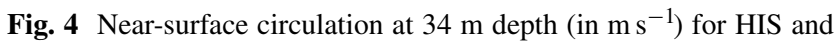
HIS-F, averaged for the 1961-1990 period. Colours represent the speed of near-surface currents gyres in the Alboran Sea (more intense in HIS-F) and then exit, either sticking to the North-African coast (HIS), or in the direction of the Balearic Islands (HIS-F). This latter path is likely unrealistic according to observations (Millot and Taupier-Letage 2005). However, a new study by Pinardi et al. (2013) shows results from a retrospective reanalysis which displays a similar northward flowing segment. Thus the realism of this "northward" branching remains under debate. After mixing with the western Mediterranean surface waters, the modified surface Atlantic waters penetrate into the eastern basin through the Strait of Sicily. The main path of the surface current remains along the southern coast but there is a branch into the mid-Ionian after passing the Sicily Strait; in HIS, this upper branch flows more northern than in HIS-F. The main path follows then the eastern coast and split into two branches: one circulates into the Aegean counterclockwise, the other travels westward below Crete. In HIS-F, the Rhodes gyre is well-noticed. Westward from Crete, the surface water penetrates then into the Adriatic with a cyclonic circulation. In the western basin, a wide cyclonic gyre, including the liguro-provencal-catalan current is present in the Gulf of Lions, surrounding the main area of deep water formation. To summarise, we found the general structure of the modelled subsurface circulation to be relatively consistent with the scheme proposed by Millot and Taupier-Letage (2005), except for the circulation in the Alboran Sea in the simulation HIS-F which displays a northward current toward the Balearic Islands, whose existence is debated.

\subsection{THC characteristics}

The Mediterranean thermohaline circulation (MTHC) is driven by salinity and temperature differences that induce a vertical circulation in the basin. This vertical circulation cell is triggered by deep and intermediate water formation, which occurs in the Gulf of Lions for the Western Mediterranean Deep Water (WMDW), in the Adriatic and Aegean basins for the Eastern Mediterranean Deep Water (EMDW), depending if we are in a classical configuration or in a EMT-like circulation, and finally in the Levantine basin for the Levantine Intermediate Water (LIW). Note that the shelf cascading is probably not well reproduced due to low resolution and z-level vertical discretization.

There are no direct observations of the intensity of the MTHC. However, some approximation of the dense water formation rate in specific regions can be found in the literature. The winter mixed layer depth (MLD) can also be used as an index to assess the convective areas and the intensity of the convection. From the model outputs, another way to assess the MTHC is to compute the overturning stream functions in $S v$ for different basins of the Mediterranean. Whereas the meridional overturning stream 
Fig. 5 Zonal overturning stream function of the Mediterranean averaged of the 1961-1990 period for HIS and HIS-F; over 2070-2099 for A2, A2-F, A2-RF, A2-ARF, A1B$\mathrm{ARF}$ and $\mathrm{B} 1-\mathrm{ARF}$. The interval between the isolines is $0.2 \mathrm{~Sv}$
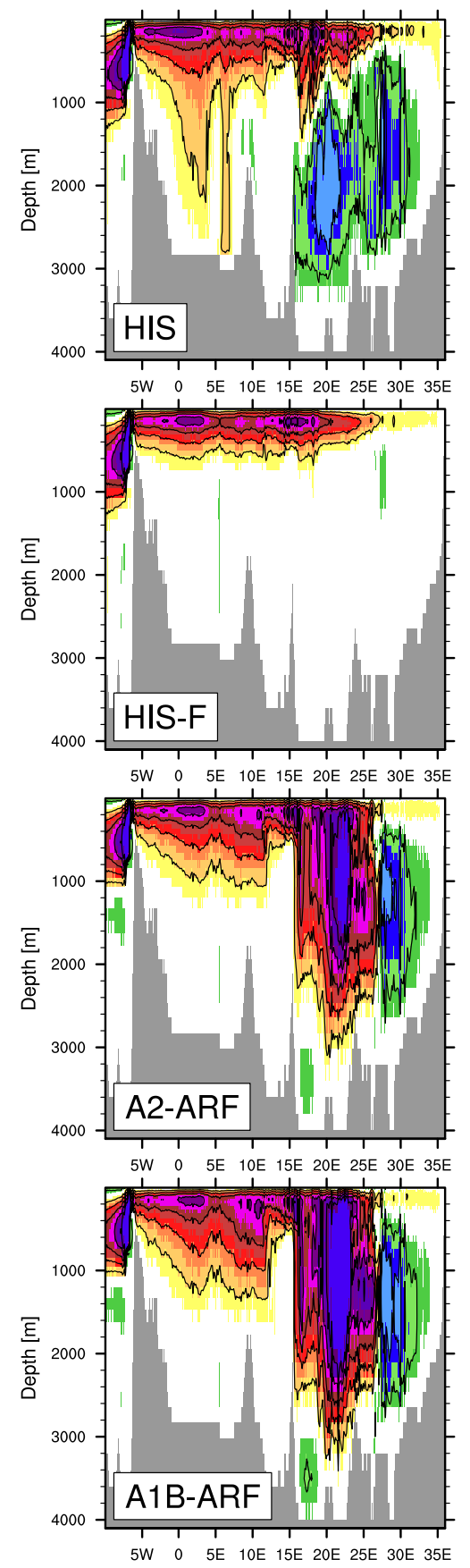

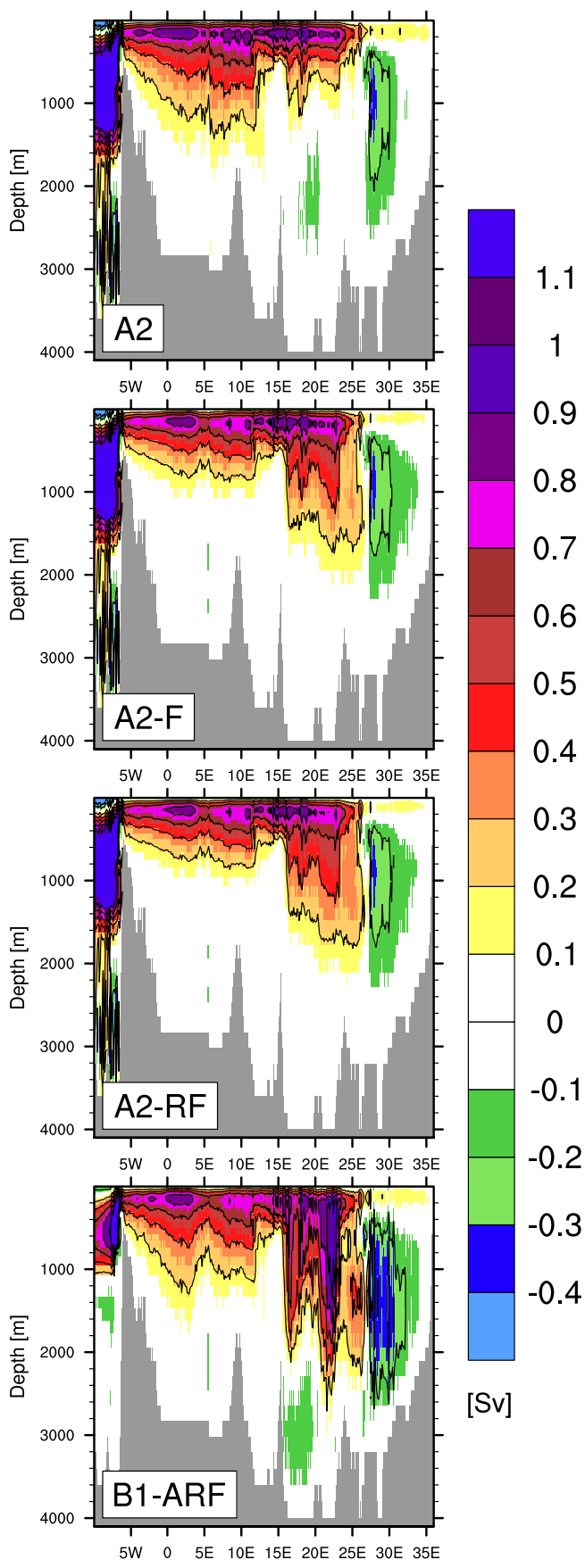

Table 6 Comparison of the maximum strength of different MTHC cells (in Sv) for the historical simulations and other simulations from the literature

\begin{tabular}{lllll}
\hline Experiment & Western basin maxima & Eastern basin maxima & Eastern basin minima (Ionian) & Eastern basin minima (Levantine) \\
\hline HIS & 1.0 & 1.1 & $-0.6(2,000 \mathrm{~m})$ & $-0.7(1,500 \mathrm{~m})$ \\
HIS-F & 0.9 & 0.9 & & $-0.2(1,000 \mathrm{~m})$ \\
Somot et al. (2006) & 1.5 & 1.2 & $-0.6(1,800 \mathrm{~m})$ & $-0.8(1,300 \mathrm{~m})$ \\
Myers and Haines (2002) & 1.5 & 0.9 & $-0.3(1,000 \mathrm{~m})$ & $-0.1(500 \mathrm{~m})$ \\
\hline
\end{tabular}


Fig. 6 Meridional overturning stream function of the Adriatic basin averaged of the 19611990 period for HIS and HIS-F ; over 2070-2099 for A2, A2-F, A2-RF, A2-ARF, A1B-ARF and B1-ARF. The interval between the isolines is $0.1 \mathrm{~Sv}$
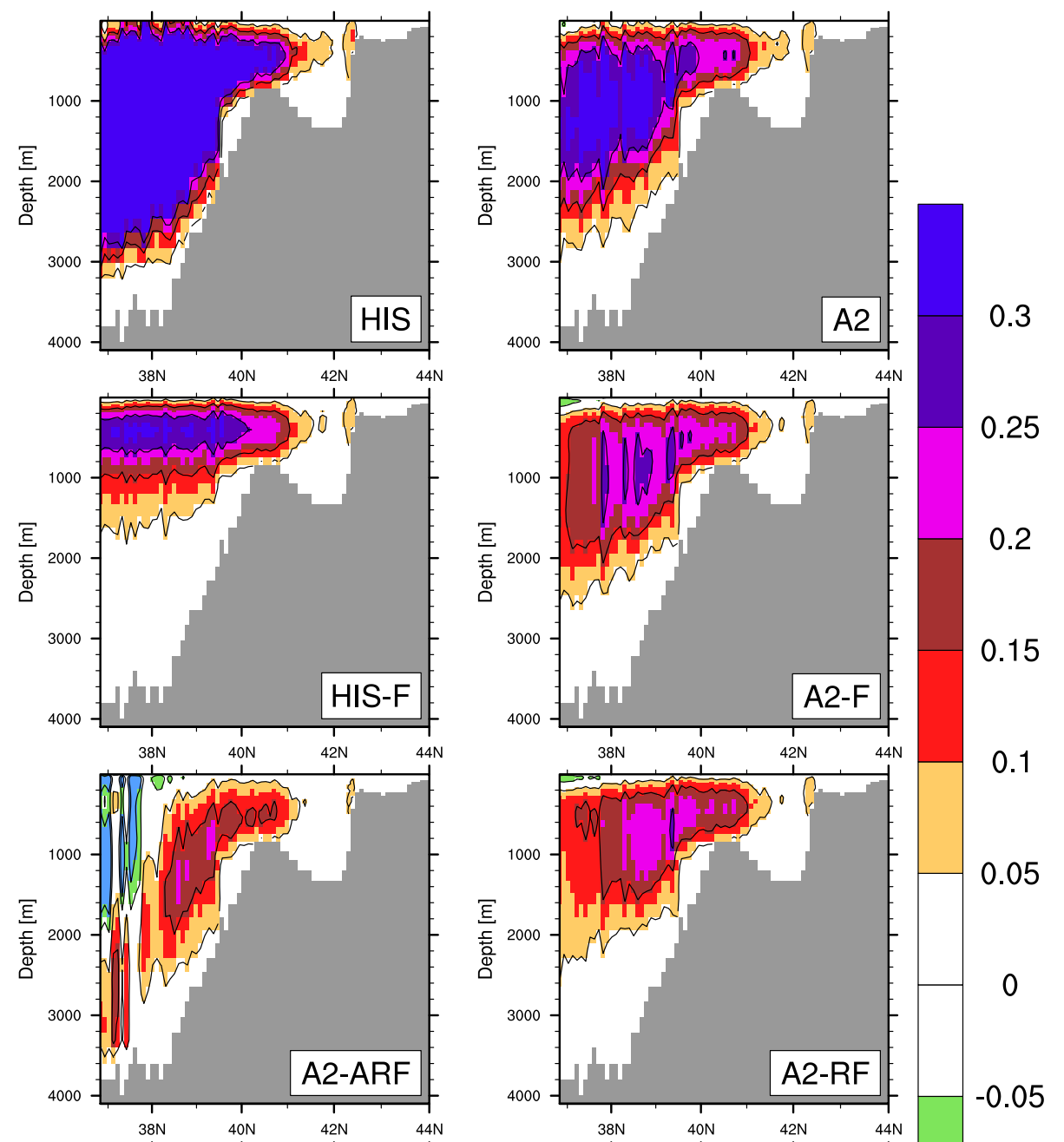

0.1
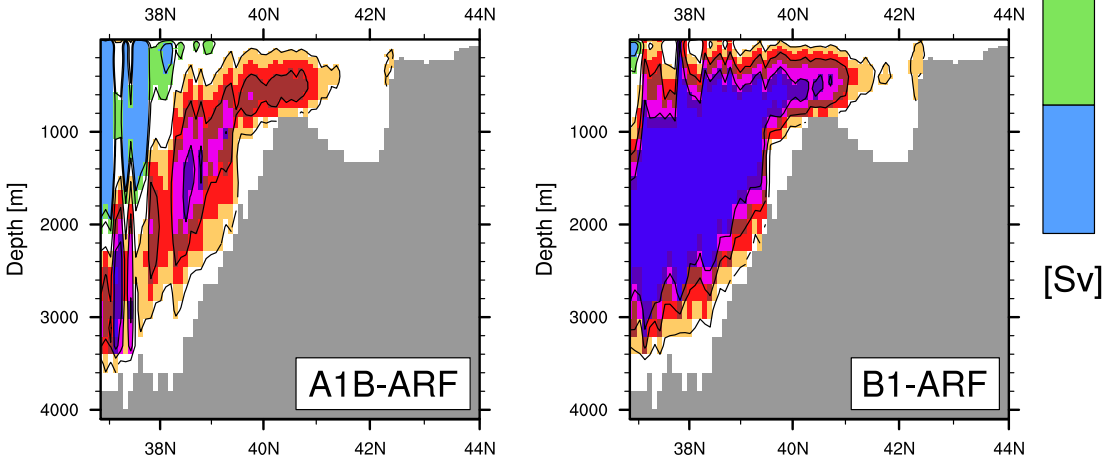

$-0.1$ function (MOF) is commonly used to assess the strength of the Atlantic thermohaline circulation, the zonal overturning stream function $(\mathrm{ZOF})$ is rather calculated for the Mediterranean. The $\mathrm{ZOF}$ has been used by Myers and Haines (2002) in their study to assess the stability of the MTHC, and later by Somot et al. (2006) to study the changes of the MTHC under climate change scenarios. Following this method, we calculate the zonal overturning stream function of the Mediterranean. The ZOF is a meridional integration from the South $\left(y_{S}\right)$ to the North $\left(y_{N}\right)$ of the zonal velocity $u(x, y, z)$, which is then integrated from the bottom of the sea $h_{b o t}(x, y)$ upward. This stream function is given by the following equation:

$\operatorname{ZOF}(x, z)=-\int_{h_{b o t}}^{z} \int_{y_{S}}^{y_{N}} u(x, y, z) d y d z$

Figure 5 shows the ZOF for the two historical experiments. The MTHC is characterised by two main circulation cells. The first cell covers both the western and the eastern basins, and has a clockwise circulation with a main path of Atlantic surface water travelling toward the east, and Levantine intermediate water travelling from the east to the west. In 
Fig. 7 Meridional overturning stream function of the Aegean basin averaged of the 19611990 period for HIS and HIS-F ; over 2070-2099 for A2, A2-F, A2-RF, A2-ARF, A1B-ARF and B1-ARF. The interval between the isolines is $0.1 \mathrm{~Sv}$
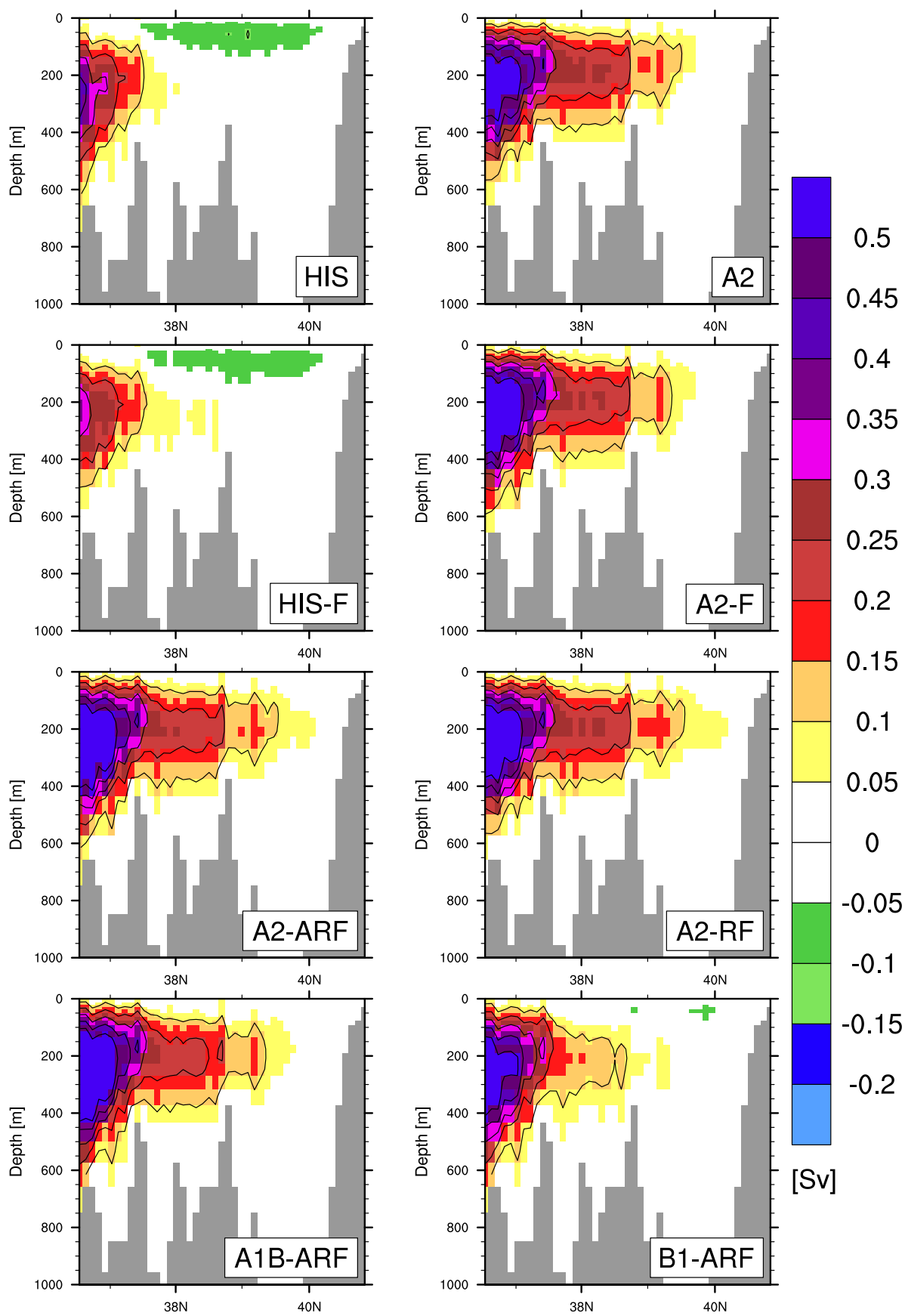

HIS, this cell has a maximum of $1.0 \mathrm{~Sv}$ at subsurface depth, between 100 and $200 \mathrm{~m}$ depth. In HIS-F, the clockwise cell is weaker (maximum of $0.9 S v$ ) and flatter (Fig. 5). These values are generally weaker than in the modelling studies by Somot (2005) and Myers and Haines (2002) (comparison shown in Table 6).

Located in the eastern basin, the second cell shows a deep counterclockwise vertical circulation. It corresponds to the circulation of EMDW toward the extreme east of the basin, this being compensated by a subsurface flow of LIW from the northern Levantine toward the west. In HIS, this cell has a negative maximum of $-0.5 S v$ in both Ionian and Levantine basins. In HIS-F, the deep counterclockwise cell is restricted to the Levantine basin, east of $25^{\circ} \mathrm{E}$, and is $-0.2 S v$. In general, HIS-F displays a rather weak deep vertical circulation cell in comparison with former numerical studies (Table 6), whereas HIS has a strong vertical circulation in the east. Despite their large differences, it is quite interesting to have two historical simulations with such contrasted vertical stratification states because it can give some hints about the impact of the initial state on the Mediterranean response to climate change. However, it is worth 

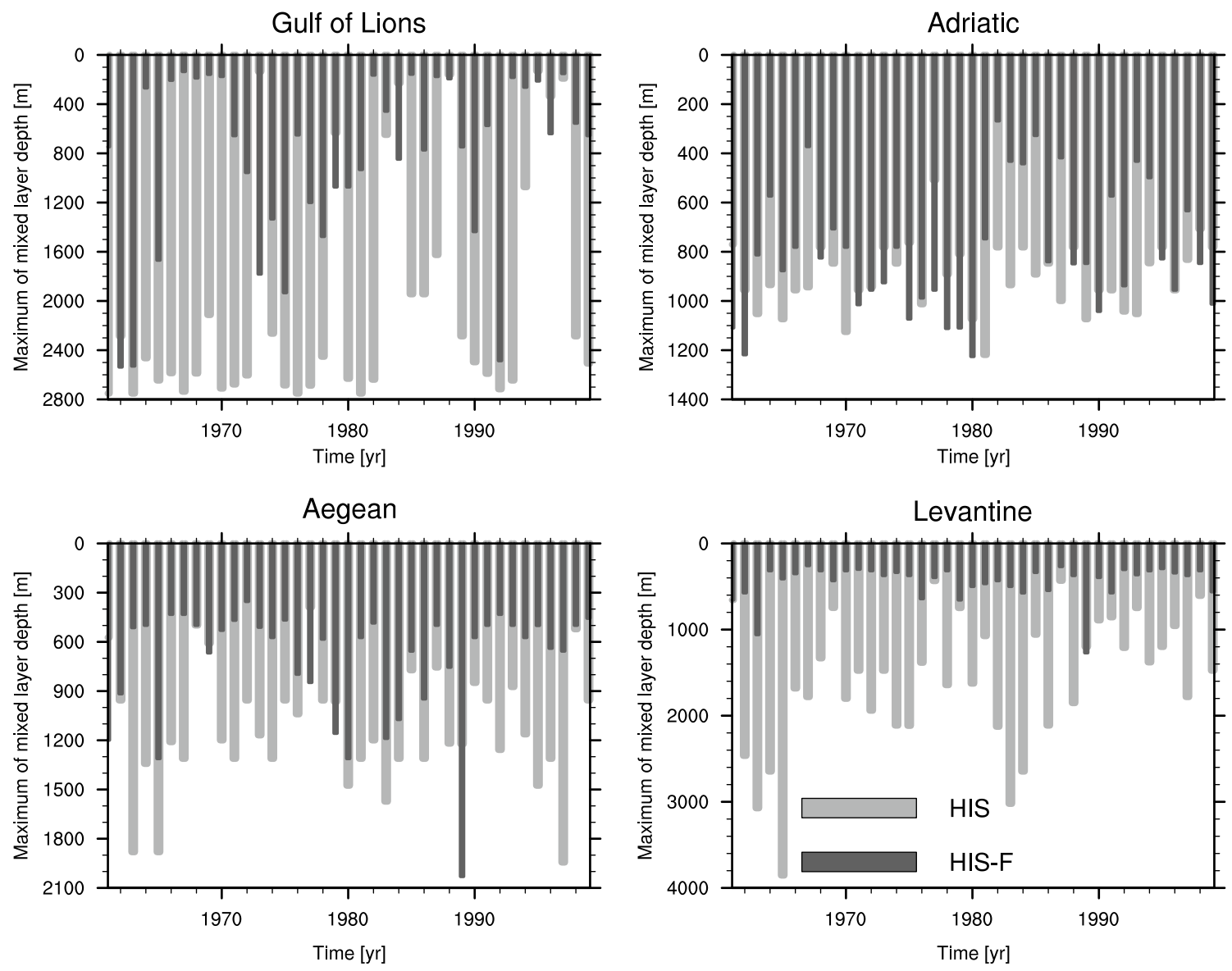

Fig. 8 Yearly maximum of mixed layer depth (in m) calculated from daily outputs for the period 1961-1999 in HIS and HIS-F simulations

mentionning that we can not establish a direct link between the vertical stratification and the deep water formation in the Ionian Sea because the EMDW is not formed locally.

The MTHC also has meridional components. It is for example useful to compute the MOF to assess the formation of Adriatic deep water (ADW) and its cascading in the Ionian basin south of the Otranto Strait. This quantity is displayed in Fig. 6 and shows the formation of ADW in the South Adriatic (between $40^{\circ} \mathrm{N}$ and $42^{\circ} \mathrm{N}$ ). The export of dense water through the strait of Otranto is of $0.3 S v$ in HIS and $0.2 S v$ in HIS-F. South of the Strait of Otranto (south of $40^{\circ} \mathrm{N}$ ), the deepening of the vertical cell represents the cascading of ADW in the Ionian basin where it mixes and becomes EMDW. For this feature, HIS is more realistic that HIS-F where the ADW does cascade a little but does not reach the bottom of the Ionian Sea. Another local MOF can be calculated for the Aegean Sea to define the formation of dense water in this region. Figure 7 displays the MOF for the Aegean Sea. The formation of intermediate water is modeled in the Aegean basin with a transport of $0.4 S v$ in HIS and $0.3 S v$ in HIS-F in the southern part. In HIS-F, the vertical circulation cell is extended until $39^{\circ} \mathrm{N}$.
The ZOF and MOF features presented before represent a mean state of the deep circulation. However the Mediterranean Sea is characterised by a strong interannual variability in terms of deep water convection, which does not reach the bottom every single year. To assess this variability in the model, Fig. 8 shows time series of the yearly maximum in space and time of daily MLD calculated with a density criterion of $0.01 \mathrm{~kg} \mathrm{~m}^{-3}$ in the sub-basins where dense water forms. This figure shows that the deep convection is more active in HIS than in HIS-F, which is consistent with the IS diagnostics (Fig. 3). When compared with the little amount of observations of the convection in the Gulf of Lions during the past decades, the modelled convection seems too weak in HIS-F and too strong in HIS. In the eastern basin, especially in the Levantine, HIS-F seems to behave better in terms of dense water formation. Besides, both simulations appear to be relatively stable for the period 19611999 and show a realistic interannual variability.

A spatial representation of the areas of dense water formation is represented in Fig. 9 which displays the winter (JFM) MLD averaged over the years 1961-1990. Figure 10 displays the comparison with the climatology by Houpert 
Fig. 9 Winter (JFM) mixed layer depth (in m) for 19611990 in HIS and HIS-F

Fig. 10 Winter (JFM) mixed layer depth anomalies (in $\mathrm{m}$ ) for 1961-1990 in HIS and HIS-F compared with the climatology of Houpert et al. (2014)
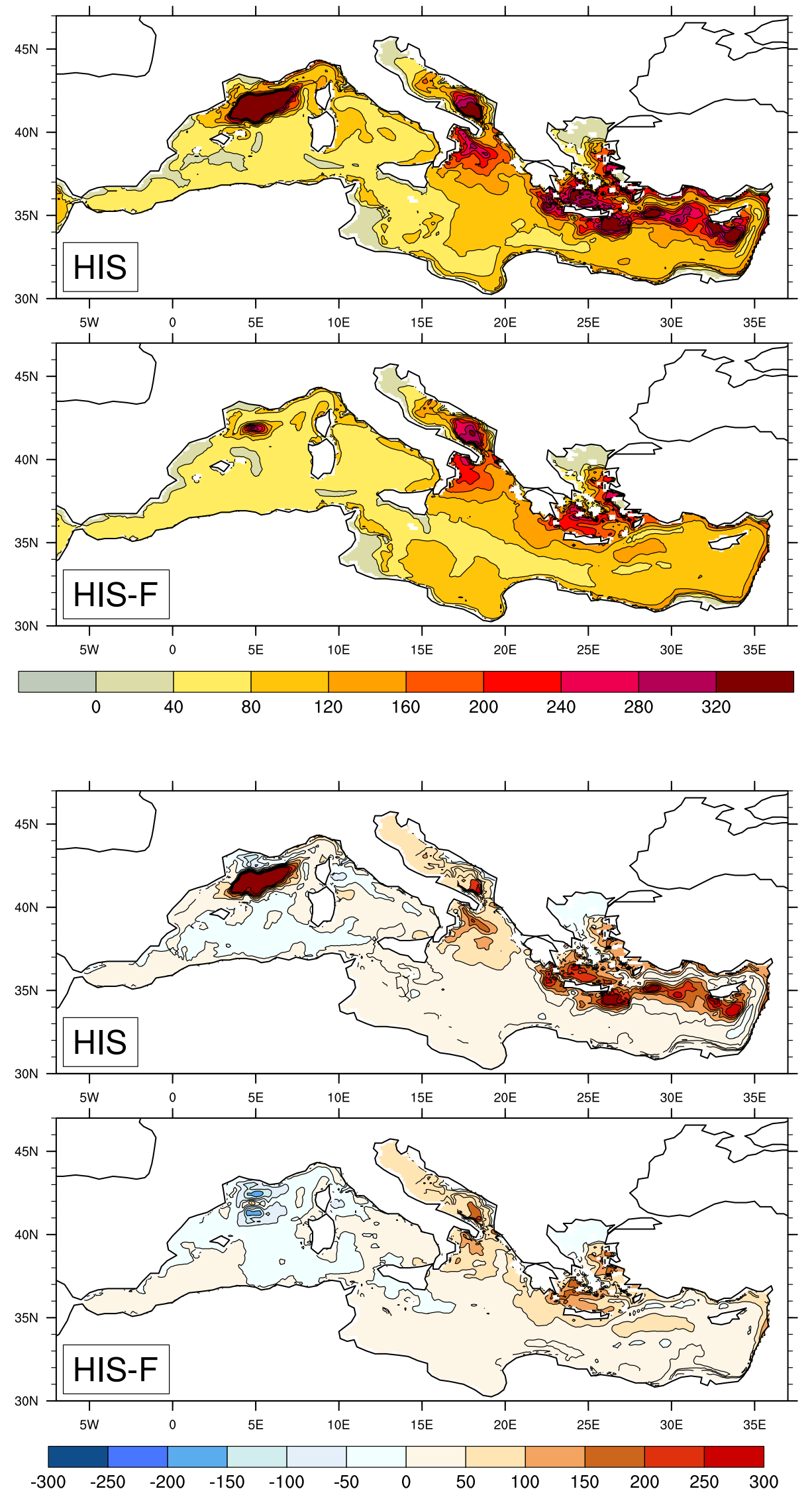
et al. (2014) and shows that HIS overestimates the winter mean dense water formation at all the main locations, whereas HIS-F compares better with the climatological data in both eastern and western basins.

To illustrate the future changes in MTHC, we set an EMT-index to qualify the type of circulation we may face in the future, especially in the eastern basin found to be the most sensitive. The EMT-index characterizes the EMT-situation, when the Aegean is the main contributor for eastern dense water production. The EMT-index corresponds to the difference between the maximums of the Levantine deep negative circulation cell and the Ionian deep positive circulation cell (Fig. 5), and applies only when the Ionian presents an intermediate/deep positive circulation cell, characteristic of the EMT. The highest the index the more we simulate an EMT-like circulation. When the index is 0, the vertical circulation corresponds to the "standard" situation, with a negative intermediate/deep circulation cell in the Ionian. The EMT-index will be used in Sect. 4.2.4 to asses the changes in water masses dynamics in the scenario simulations.

\subsection{Model evaluation synthesis}

This section aims to discuss the realism of both historical simulations presented in this study and compare our results with other modelling studies. Concerning the heat budget, both simulations are realistic with values of -6 and $-4 \mathrm{~W} \mathrm{~m}^{-2}$ and compare well with the value of $-7 \mathrm{~W} \mathrm{~m}^{-2}$ by Pettenuzzo et al. (2010) and the value of $-1 \pm 8$ gathered by Sanchez-Gomez et al. (2011). For the net water budget, our simulations perform better than the historical simulation in Somot et al. (2006) and most of the historical simulations by coupled models presented in the study by Dubois et al. (2012) over the same period. Moreover, our values are very consistent with the compilation of observation estimates by Sanchez-Gomez et al. (2011). However the hydrological cycle is too strong, due to an overestimation of $\mathrm{P}$ and $\mathrm{E}$ by ARPEGE-Climat, both values being far out of the range of the observational estimates and worse than the values in other models presented in Dubois et al. (2012). With respect to heat and salt content, we improve the results compared to Somot et al. (2006), especially for the heat content over the full water column. The averaged SST and SSS have also been improved, especially in the HIS-F simulation. Compared to the historical simulation E20C in Carillo et al. (2012), our both simulations HIS and HIS-F display more consistent heat and salt content values, considering MEDATLAS-II as reference. Concerning the surface circulation, HIS and HIS-F are quite consistent with the circulation pattern proposed by Millot and TaupierLetage (2005), except for the northward branch from the Alboran Sea to the Balearic Islands displayed in HIS-F.
However, this pattern is found in the reanalysis by Pinardi et al. (2013). The subsurface circulation in HIS-F has similar qualities and drawbacks as the stand-alone ocean simulation of Beuvier et al. (2010). In addition, the formation of deep water and the associated MTHC is quite different in our two historical simulations. HIS has a too strong vertical circulation whereas HIS-F has a too weak vertical circulation, especially in the western basin. Because of the lack of long-term observations, the evaluation of the MTHC and of the dense water formation in Mediterranean ocean models is non-trivial. However, we do not claim that our simulations display the most-realistic MTHC but they represent a range of "possible situations". In summary, the model configuration used here is able to reproduce the main features of the Mediterranean Sea hydrography and circulation with at least similar skills than state-of-the-art models. Therefore, it is expected that the model will be able to reflect the impact of climate change on the functioning of the Mediterranean hydrography and dynamics.

\section{Projections under climate change scenarios}

\subsection{The SRES scenarios}

The socio-economic scenarios used in the present study are based on the Special Report on Emissions Scenarios (SRES). Among the three scenarios which have been performed, B1 is the most optimistic, A2 is the most pessimistic and $\mathrm{A} 1 \mathrm{~B}$ is intermediate in terms of gases emissions.

The A2 scenario has been developed in the frame of the Third Assessment Report (TAR) of the Intergovermental Panel on Climate Change (IPCC), and is one of the worst scenarios in terms of greenhouse gas emissions. It is based on the following asumptions: a continuously increasing population, a regionally oriented economic development and a world of self-reliant nations.

\subsection{Future Mediterranean climate}

\subsubsection{Surface fluxes}

As depicted in Table 2, E-P-R-B increases for all the projections for the period 2070-2099 compared with the historical period 1961-1990. Precipitation, runoff and Black Sea freshwater input tend to decrease whereas the evaporation increases, consistently with the studies by Mariotti et al. (2008), Sanchez-Gomez et al. (2009), Elguindi et al. (2011) and Dubois et al. (2012). To compensate the resulting enhanced water loss, the net water inflow at Gibraltar is intensified. These changes are strongly influenced by the choice of the scenario with the strongest effect under the A2 scenario, and the weakest effect under the moderate 
scenario B1, A1B being intermediate. As in Somot et al. (2006) and Dubois et al. (2012), we found a decrease of the surface net heat loss (Table 3 ) in all projections. Note that none of the scenarios shows a surface heat gain in 20702099 what means that the atmosphere still extracts heat from the Mediterranean Sea at the end of the twenty-first century. This change varies according to the scenario used, but also strongly depends on the chosen boundary conditions. The latest point will be investigated in Sect. 4.3.

We found a general decrease of the Mediterranean surface potential density (Fig. 11; Table 5) because the increase of the SSTs (Fig. 12) prevails on the increase of SSSs (Fig. 13). This is not true for B1-ARF where the surface density increases because the density gain from the saltening prevails on the density decrease from the warming. In the scenarios, the SSTs become warmer with a range between +1.7 and $+3{ }^{\circ} \mathrm{C}(2070-2099$ vs. $1961-$ 1990, averaged over the Mediterranean) and this large

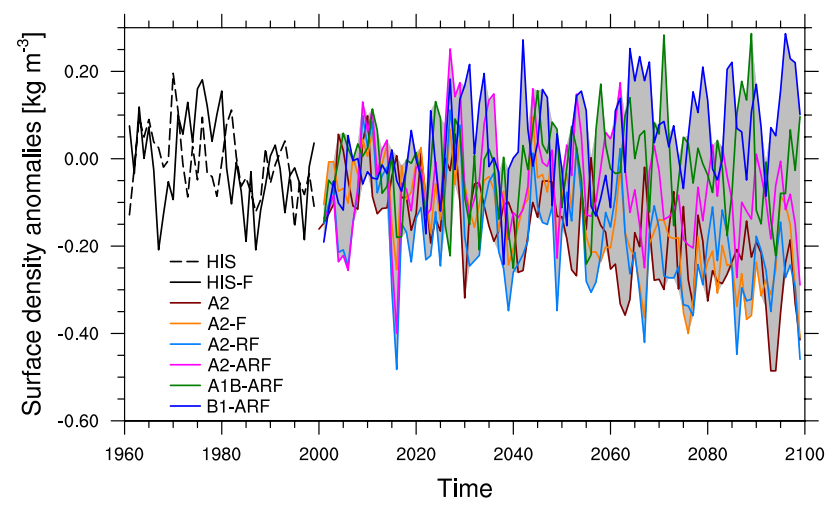

Fig. 11 Yearly mean time series of sea surface density anomalies (vs. 1961-1990) averaged over the Mediterranean basin. The spread of the ensemble is shaded in grey

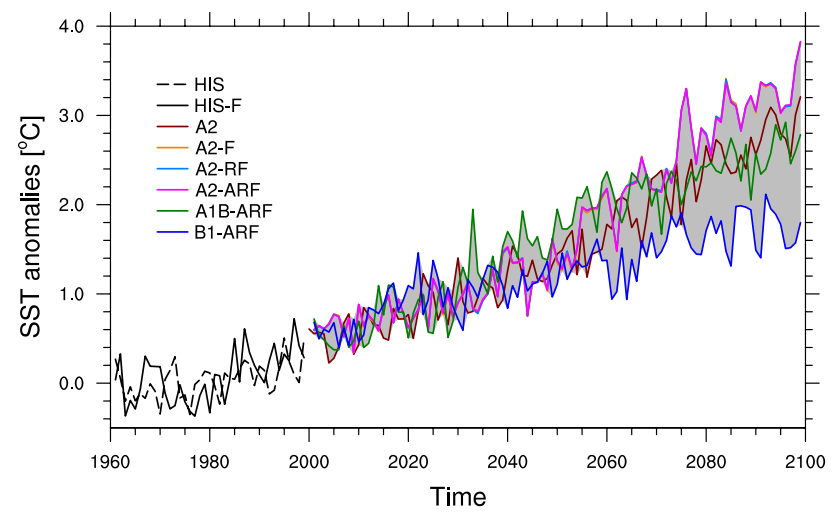

Fig. 12 Yearly mean time series of sea surface temperature anomalies (vs. 1961-1990) averaged over the Mediterranean basin. A2-F, A2-RF and A2-ARF curves are overlapping. The spread of the ensemble is shaded in grey

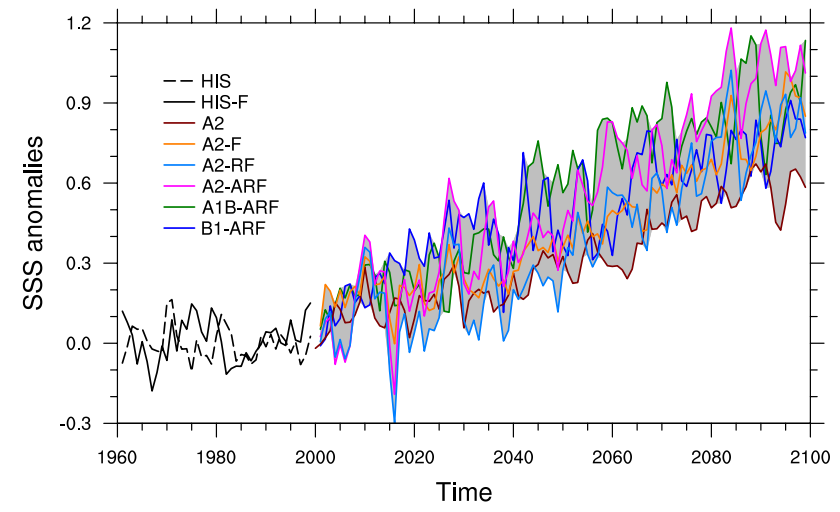

Fig. 13 Yearly mean time series of sea surface salinity anomalies (vs. 1961-1990) averaged over the Mediterranean basin. The spread of the ensemble is shaded in grey

spread reflects the sensitivity to the chosen scenario. The SST term has a low sensitivity to the boundary conditions due to the use of the SST relaxation term (Table 4; Fig. 12). Figures 14 and 15 represent the composites of the SST and SSS anomalies maximums and minimums: the largest or smaller anomaly out of the 6 scenario simulations is taken into account at each grid point. These figures show that the warming is not homogenous: the region of the Balearic Islands, the Northwest Ionian, the Aegean and Levantine Seas get warmer than the average (Fig. 14). Concerning the SSS, it generally increases with a range between +0.48 and +0.89 (Fig. 13) and the interannual standard deviation of the historical simulations is 0.07 in HIS and 0.08 in HIS-F. As for the SST, the SSS anomaly signal is not homogenous: the Aegean basin is getting saltier than the rest of the Mediterranean and both Balearic region and North Ionian display a weaker response, even a freshening in some simulations (Fig. 15). The choice of the scenario (experiments A2-ARF, B1-ARF and A1B-ARF) does not induce too strong variations in the SSS anomalies but the choice of the boundary conditions does (experiments A2, A2-F, A2-RF and A2-ARF), especially the choice of the Atlantic salinity (Fig. 13). The warming and saltening of the Aegean are mainly explained by the strong decrease of the net water input from the Black Sea, whereas the other strong patterns mainly refer to subsurface circulation changes (Sect. 4.2.3). In Figs. 14 and 15, it is worth noting that in most of the cases, the SST MAX map corresponds to the scenario A2-ARF, the SST MIN to B1-ARF, SSS MAX to A2-ARF and SSS MIN to A2.

\subsubsection{Heat, salt and density contents}

A warming and saltening are modelled in all the layers of the water column (Table 4), but this signal decreases 
Fig. 14 Composite of sea surface temperature anomalies maxima (top) and minima (bottom) for the 2070-2099 period (vs. 1961-1990). The largest (maxima) or smaller (minima) anomaly out of the 6 scenario simulations is represented at each grid point. Units are in ${ }^{\circ} \mathrm{C}$
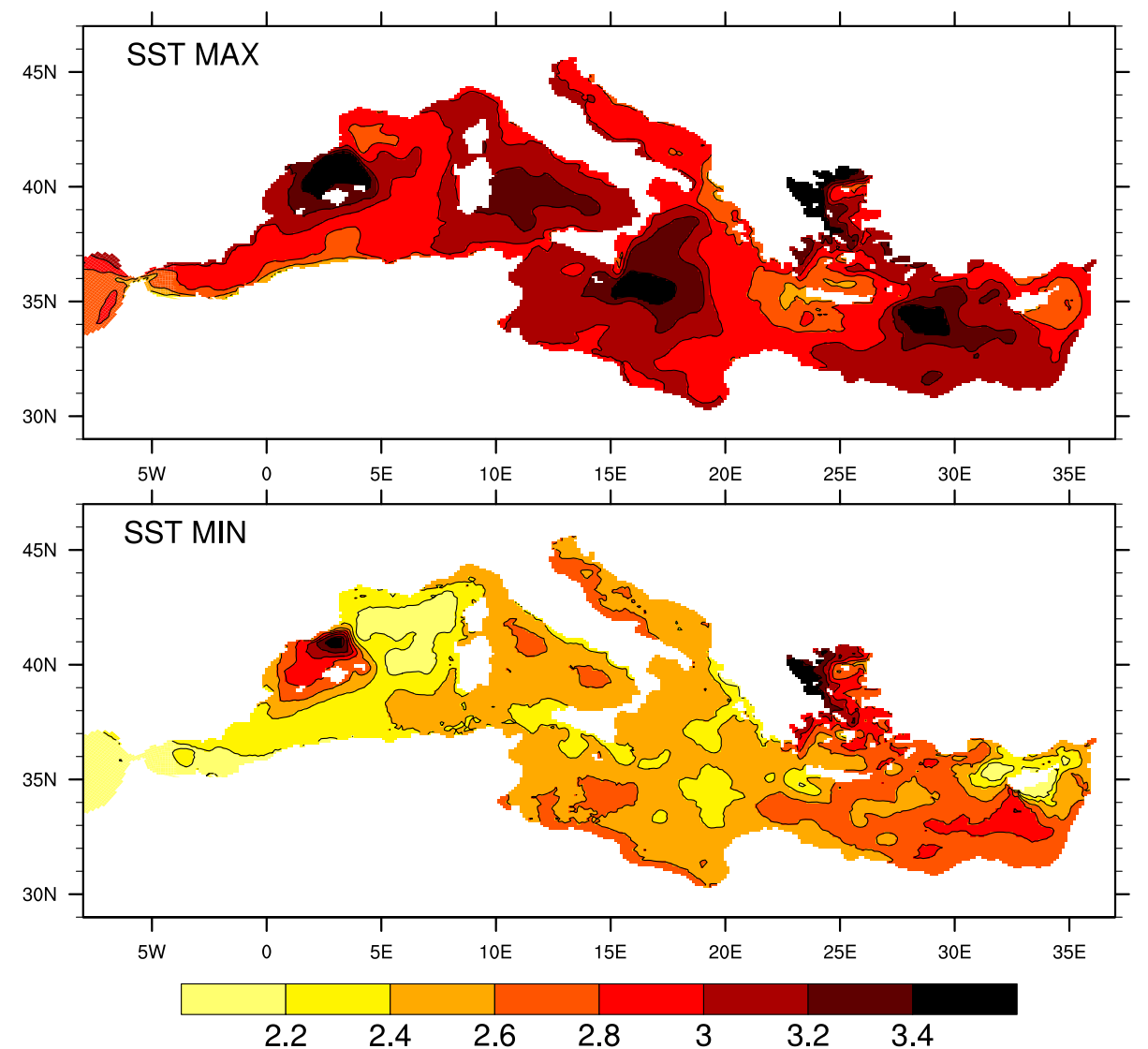

Fig. 15 Composite of sea surface salinity anomalies maxima (top) and minima (bottom) for the 2070-2099 period (vs. 1961-1990). The largest (maxima) or smaller (minima) anomaly out of the 6 scenario simulations is represented at each grid point
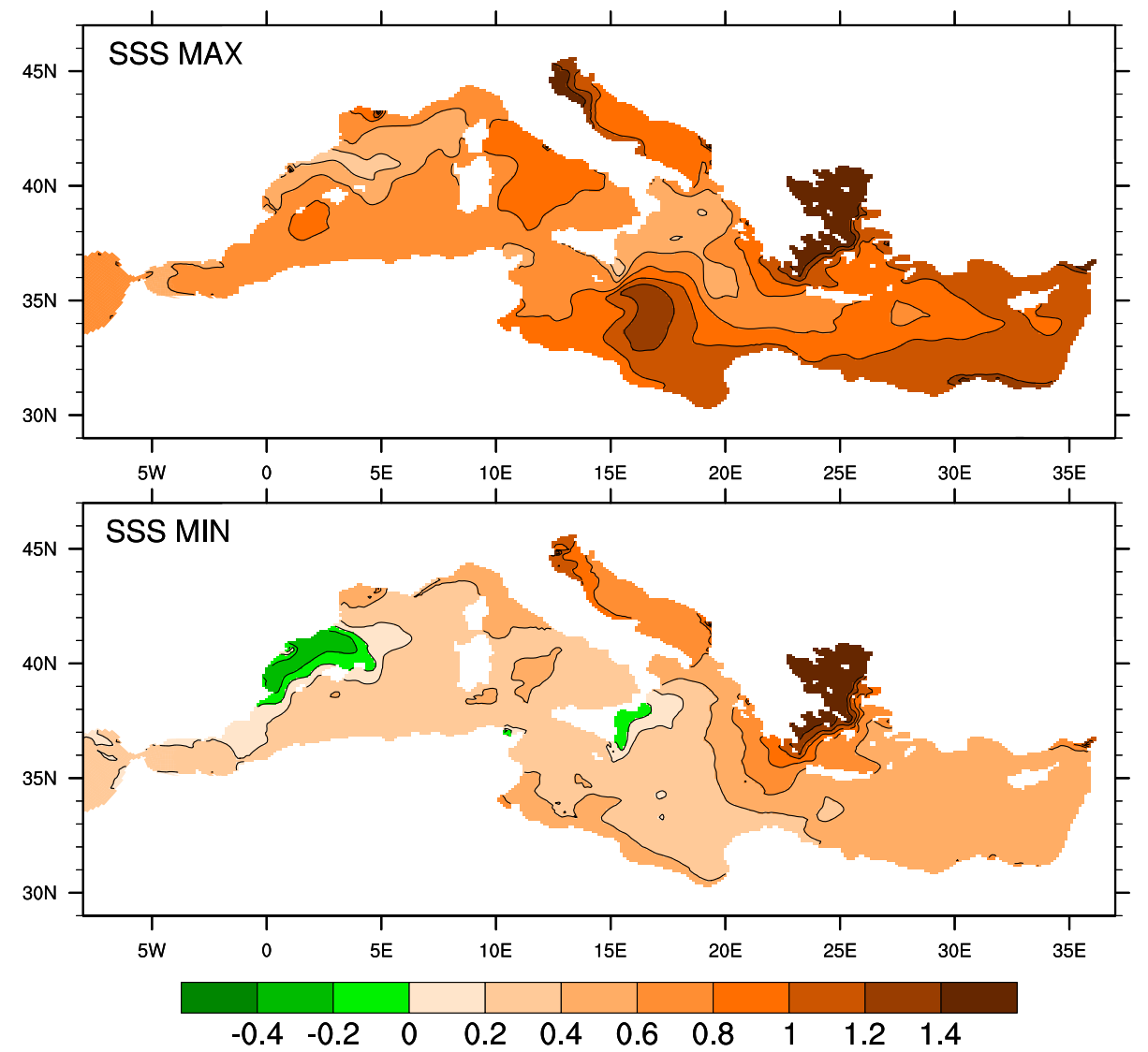


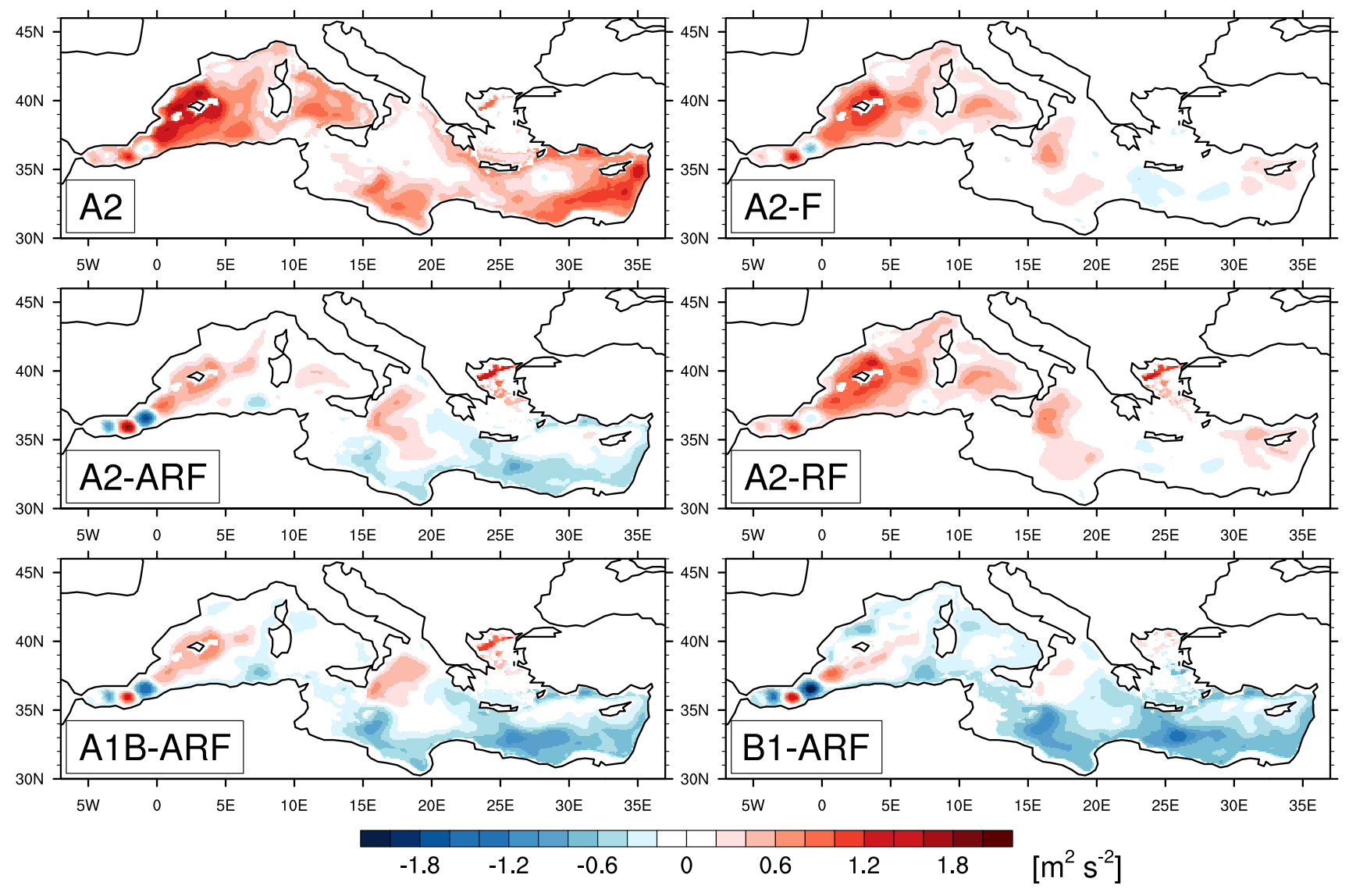

Fig. 16 Index of stratification (IS) anomalies (in $\mathrm{m}^{2} \mathrm{~s}^{-2}$ ) for the 2070-2099 period (vs. 1961-1990)

through depth from an average of +0.7 and $+2.6{ }^{\circ} \mathrm{C}$ at the surface to +0.4 and $+1.0{ }^{\circ} \mathrm{C}$ in the $600 \mathrm{~m}$-bottom layer. The penetration of the heat and salt anomalies from surface to depth varies according to the simulation, depending on the changes in convective areas, themselves influenced by the historical state of the vertical stratification and the associated MTHC. The changes of MTHC will be described in Sect. 4.2.4.

The density averaged over the whole water column increases in all the scenario simulations (Table 5). This also applies for the mean density of the layers $150-600 \mathrm{~m}$ and 600-bottom. However, the layer 0-150 $\mathrm{m}$ displays a density decrease in A2, A2-F and A2-RF: this signal is directly depending on the properties of Atlantic water entering in the Mediterranean which are lighter in these simulations. These density changes lead to changes in the vertical stratification of the basin in the future as displayed by the $I S$ anomalies (Table 5; Fig. 16). Overall, the simulations with lighter Atlantic waters from GCM2 (A2, A2-F and A2-RF) represent a strong increase of the vertical stratification whereas A1B-ARF, B1-ARF and A2-ARF display a large decrease of $I S$ in the eastern basin.

\subsubsection{Surface circulation}

Figure 17 displays anomalies of near-surface circulation at $34 \mathrm{~m}$ depth and shows a clear change in the Balearic region with the penetration of the Atlantic surface water toward the North, along the spanish coast, westward of the Balearic Islands. This feature is new if compared to HIS, or reinforced, when compared to HIS-F. However this change should be interpreted cautiously since the circulation of the historical simulation is not very realistic in this small region. In the Ionian basin, the "F" family simulations display a substantial modification of the trajectory of modified Atlantic waters into the eastern basin, which forms a "North Ionian jet", similar to the surface circulation changes which occur during the EMT. These two large changes explain both surface warming and freshening (or weaker saltening) of the Balearic region and the North Ionian mentioned in Sect. 4.2.1.

\subsubsection{THC characteristics and water masses dynamics}

Figure 5 presents the picture of the MTHC in all the simulations. The MTHC future evolution in the scenarios is 


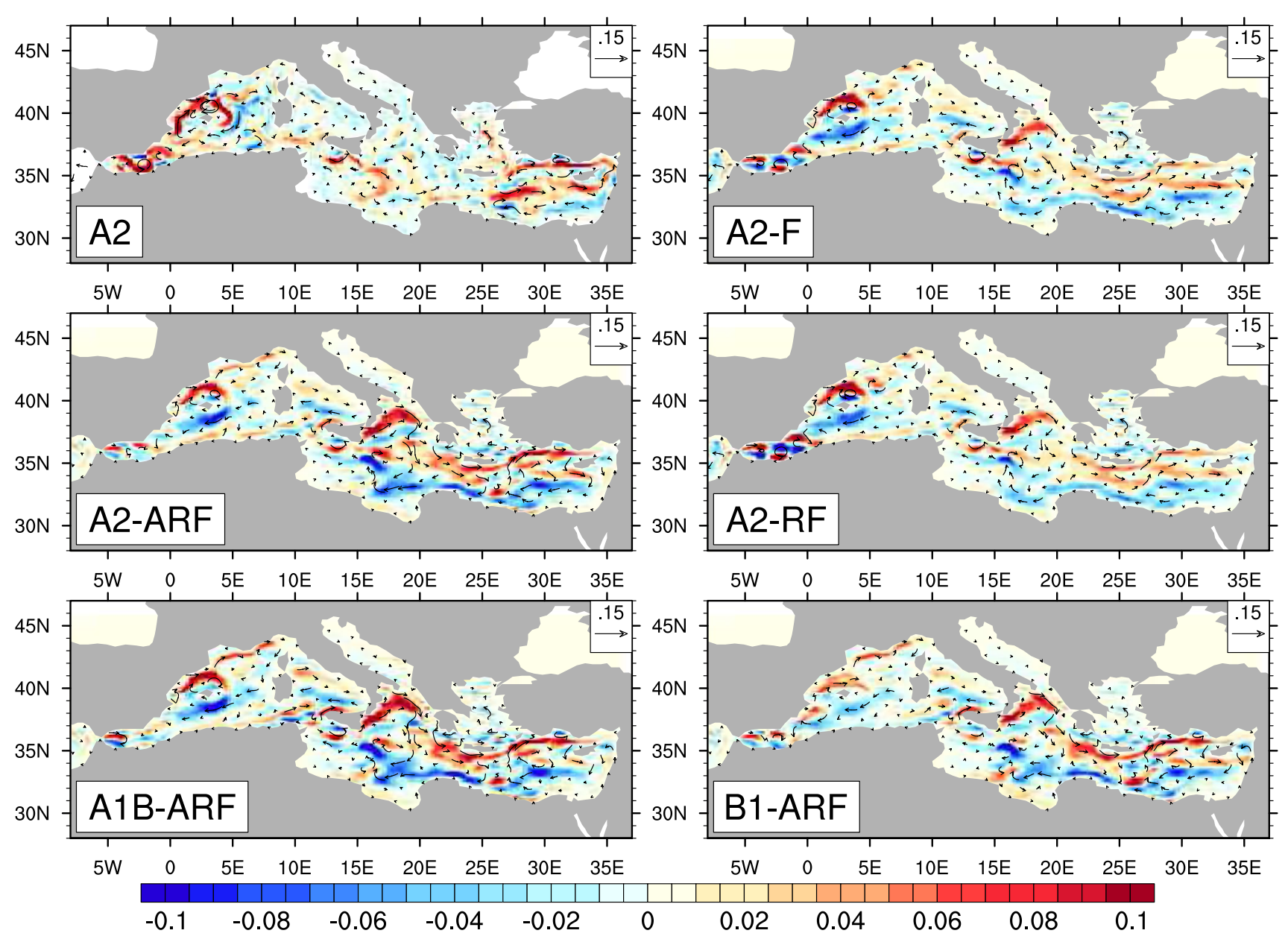

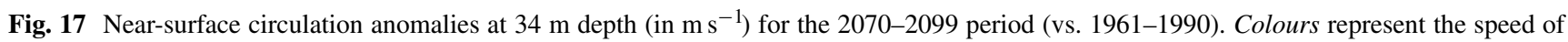
near-surface currents

strongly related with the state of the vertical stratification in the historical simulations which is weaker in HIS than in HIS-F. The large differences between both historical states provide an interesting diversity for the analysis. We first analyse the results of the "F" simulations, whose atmospheric forcing comes from RCM4.

In the "F" family simulations, despite the general increase of the MTHC, there are strong changes in the areas where dense water is formed: the eastern basin becomes generally more productive and faces a similar situation as during the Eastern Mediterranean Transient. This EMT-like situation happens because the Aegean basin experiences a buoyancy loss in comparison with the historical period, this loss is related to both intensified winds and very low net water inflow from the Black Sea, which reduce the Aegean buoyancy. This situation is clearly depicted in Fig. 5 with the increase of the negative intermediate/deep cell between $27^{\circ} \mathrm{E}$ and $35^{\circ} \mathrm{E}$, which represents the strong outflow of Aegean deep water into the Levantine basin through the straits of Kassos and Karpathos (not shown) as proposed by
Beuvier et al. (2010). The intermediate/deep positive cell between $15^{\circ} \mathrm{E}$ and $27^{\circ} \mathrm{E}$ represents the outflow of Aegean deep water into the Ionian basin through the Strait of Antikythera (not shown).

To illustrate the EMT situation, we analyse the EMTindexes (described in Sect. 3.6) averaged over the period 2070-2099 for each simulation (Fig. 18). The highest the index the more we simulate an EMT-like circulation. As expected, the historical simulations have an EMT-index set to $0 \mathrm{~Sv}$, since both simulations depict the expected "standard" circulation, with no positive intermediate/deep vertical circulation cell in the Ionian basin. The "standard situation" refers to a MTHC situation with a single source of deep water located in the Adriatic for the eastern Mediterranean. In the "F" family scenarios, the index increases with a range between 1.01 and $2.86 \mathrm{~Sv}$. In the simulation $\mathrm{A} 2$, the index stays at $0 \mathrm{~Sv}$ with a vertical circulation which weakens but keeps the standard configuration. We aim to relate the EMT-index to the Aegean buoyancy. Figure 18 represents the relation between the EMT-index anomalies 


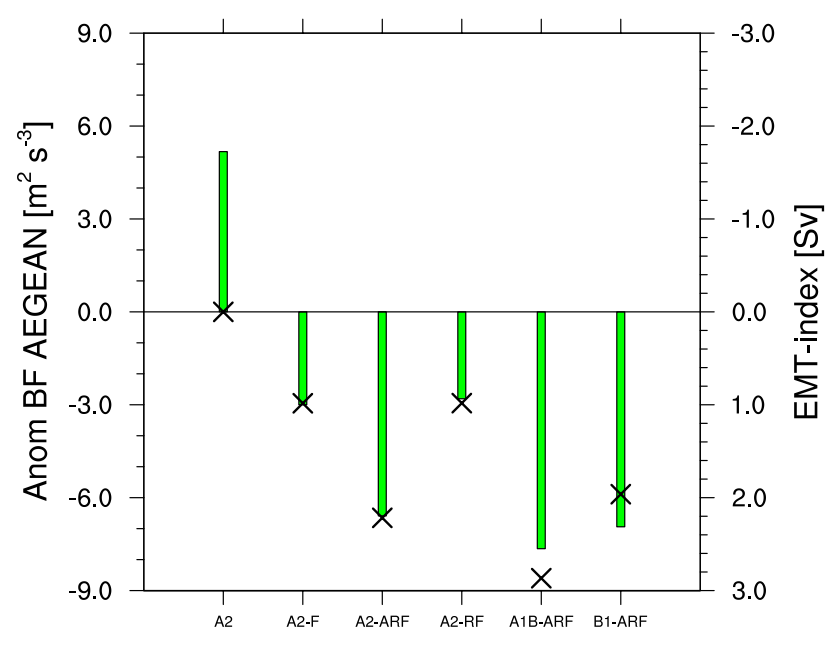

Fig. 18 Relation between Aegean buoyancy fluxes (left y axis) and EMT-index (right y axis) for each of the scenario simulations. The EMT-index calculation is explained in Sect. 3.6 and displayed as a cross. Green bars represent the intensity changes of the Aegean buoyancy fluxes

(scenario vs. historical period) and the Aegean buoyancy fluxes anomalies. From HIS to A2, the buoyancy fluxes of the Aegean basin increase, whereas they decrease from HIS-F to all the " $F$ " scenario simulations. An Aegean full buoyancy decrease clearly pushes toward an EMT situation and is mainly expected in the future Mediterranean ocean climate (as seen in A2-F, A2-RF, A2-ARF, A1B-ARF and B1-ARF).

In Fig. 5, the negative very deep cell in the Ionian basin (between $15^{\circ} \mathrm{E}$ and $27^{\circ} \mathrm{E}$ ) represents the deep circulation of the ADW which flows through Otranto, and cascades southwestward into the Ionian. The scenario simulations generally face a situation where the density difference between the ADW and the northwest Ionian water increases (in comparison with the historical period), therefore, the cascading depth of the ADW is increased from $1,265 \mathrm{~m}$ in HIS-F to a range between 1,861 and $2926 \mathrm{~m}$ in the "F" scenarios (Fig. 6). However, Fig. 6 also shows that the intensity of the circulation cell from the Adriatic into the northern Ionian weakens (but in B1-ARF) and tends to be restricted to the extreme North of the Ionian basin in A2-ARF and A1B-ARF.

From the " $F$ " simulations analysis, we can state that we head towards an EMT-circulation in the future, but the ADW production is still active: the ADW is produced with a slightly lower intensity but the cascading goes deeper and is confined in the high northern Ionian due to the presence of enhanced Aegean outflow (negative cell in Fig. 6 for A2-ARF and A1B-ARF).

Concerning the changes occurring in the western basin, the dense water production in the Gulf of Lions decreases by the end of the century in all the scenario simulations
"A2" but remains similar to the historical state in A1BARF and increases in B1-ARF whose vertical stratification diminishes in this area (Figs. 16, 19). For the western Mediterranean, we can establish a direct link between the vertical stratification in the Gulf of Lions and the deep water production since the WMDW is formed locally.

If we focus on the differences between HIS and A2 (atmospheric forcing comes from RCM3), we find a decreasing MTHC in both eastern and western basins (Fig. 5), confirming results obtained by Somot et al. (2006) who used the same forcing but another ORCM and found a decrease in the surface density associated with a weakening of the thermohaline circulation, except for the Adriatic. This significative difference of future changes is related to the fact that the HIS simulation has a low vertical stratification and is very convective (especially in the eastern basin), due to very strong winter heat loss compared to HIS-F in the historical period. However, despite a decrease of the MTHC in A2 compared to its historical period, the high-convective initial state of HIS allows to bring the surface hydrographic anomalies to deeper layers from the beginning of the A2 simulation on. This explains the large anomalies found in the deepest layer despite moderate surface anomalies compared to the "F" family of scenario simulations.

\subsubsection{Sea level changes}

The model configuration does not consider changes in the Atlantic sea level, so from this ensemble we cannot estimate future changes of total sea level. However, the thermosteric component of sea level (the one related with expansion/contraction of the water column) can be estimated from the ensemble. In the former sections, we focused on changes in the formation of the water masses and their hydrographic properties in the future. These large changes have a strong impact on the mean thermosteric sea level (Fig. 20) which results from the heat content changes over the full water column. For the 20702099 period, a mean increase between 34 and $49 \mathrm{~cm}$ is simulated. This large spread is explained by differences in the convective areas and in the intensity of the convection, leading to differences in the transfer of the surface heat to the deepest part of the basin, thus impacting the basin heat content and the thermosteric sea level. It is important to highlight that this range of values (34-49 $\mathrm{cm}$ ) only refers to the thermosteric component of sea level. To recover total sea level other components should be included (e.g. mass addition due to land ice melting, changes in the Atlantic circulation,...). From the recent 5th IPCC report (IPCC 2013), it seems that those components will be positive adding between 15 and $30 \mathrm{~cm}$ to the thermosteric component. 
Gulf of Lions

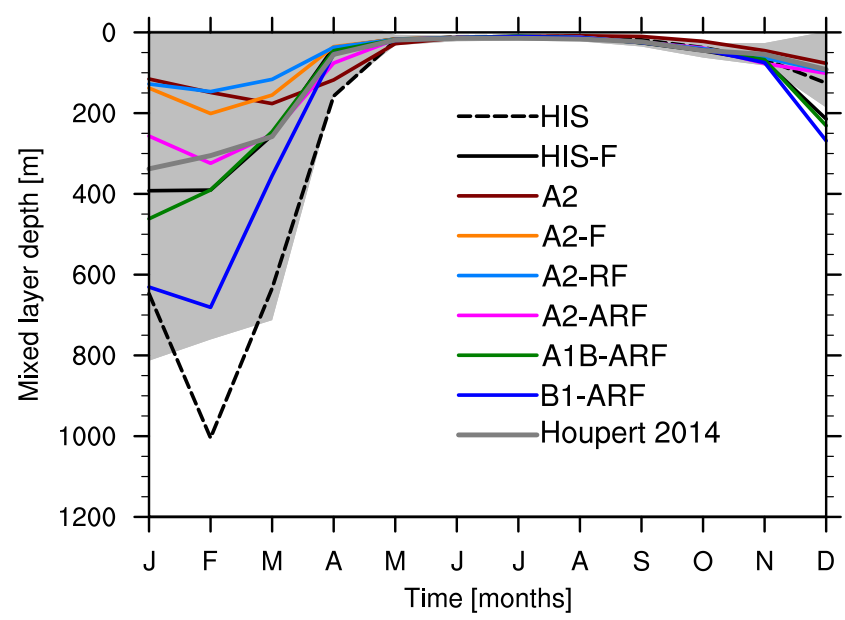

Aegean

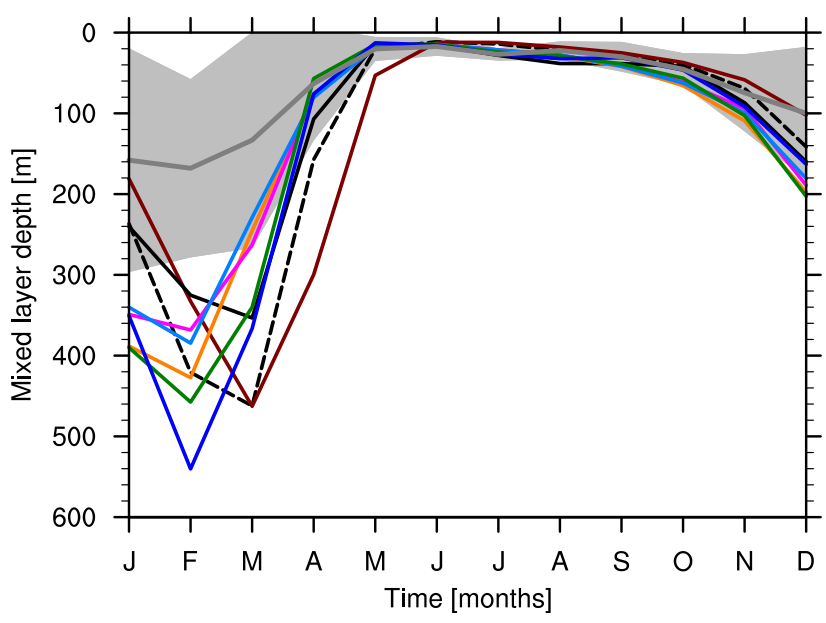

Adriatic

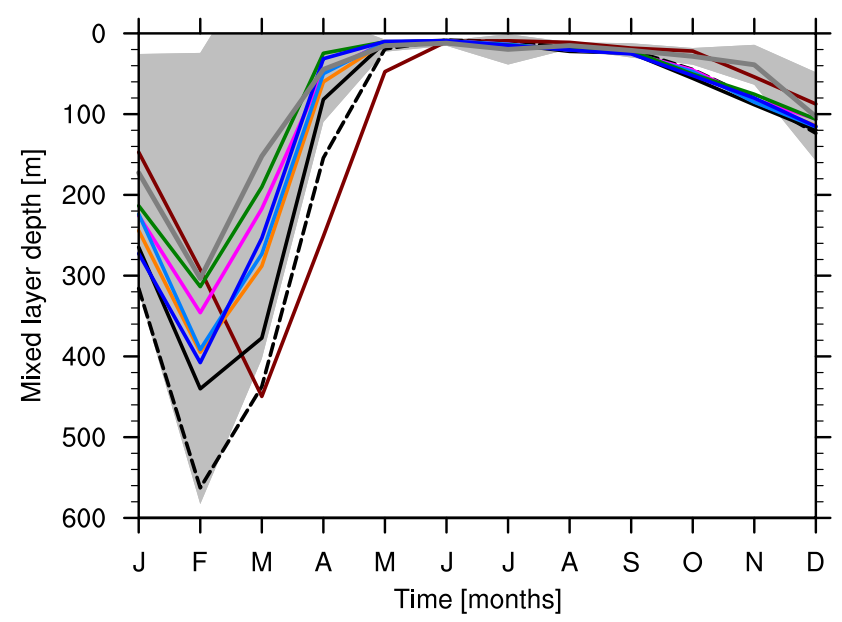

Levantine

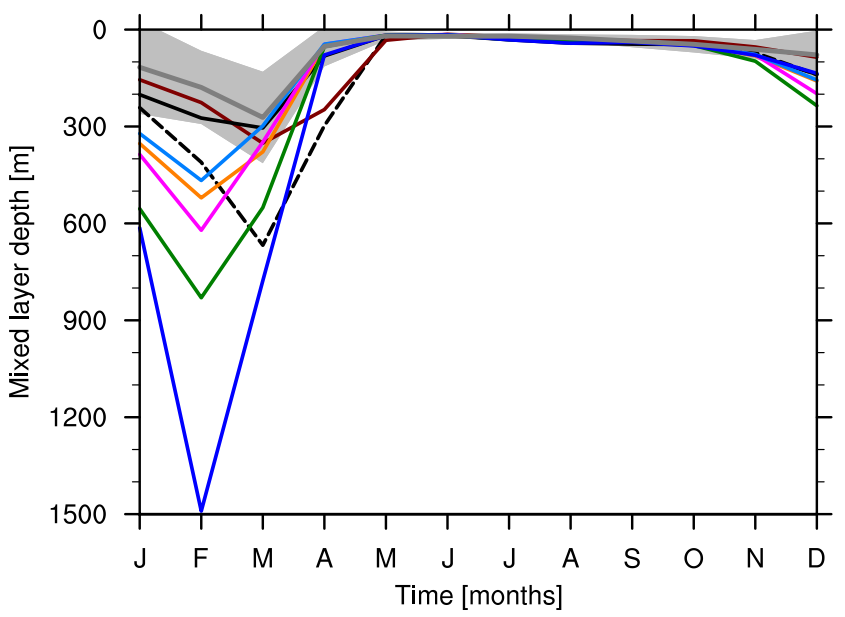

Fig. 19 Monthly climatology of the mixed layer depth (in m) for the period 1961-1990 for HIS and HIS-F, and the period 2070-2099 for the scenarios. Model results are compared with the climatology of Houpert et al. (2014), the spread refers to the standard deviation

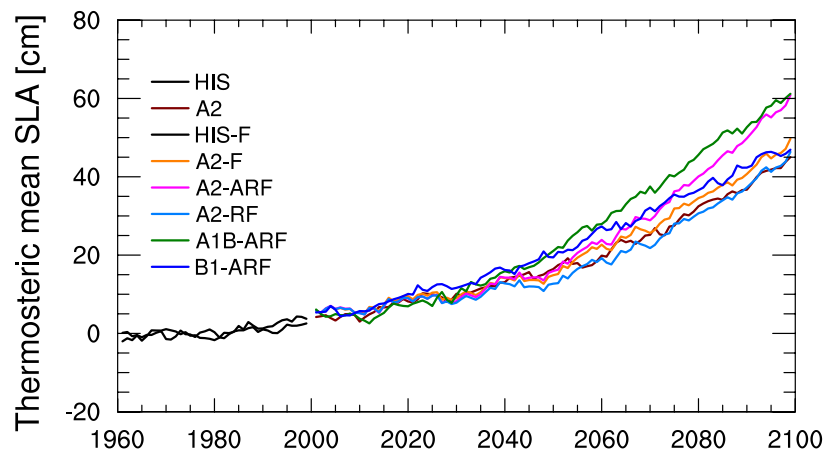

Fig. 20 Yearly mean time series of thermosteric mean sea level anomalies (in $\mathrm{cm}$ ) averaged over the Mediterranean basin for all the simulations (vs. 1961-1990)

\subsection{Sensitivity to boundary conditions}

This section aims to identify and quantify the impact of the different boundary conditions on the obtained results for a given scenario. We examine the sensitivity of the future Mediterranean Sea to the prescribed hydrography of the Atlantic water, the river runoff and the surface fluxes. For that purpose, we only focus on A2 scenario simulations. In each of the analysed simulations, the combination of boundary forcing changes in such a way that we can isolate the sensitivity to each type of boundary forcing, by comparing simulations one to one. The uncertainty range explored in the present study can be small compared to the large spread displays among other regional and global 
models regarding the future changes in Atlantic hydrography, river runoffs and atmospheric fluxes. This point is discussed in Sect. 4.6.

\subsubsection{Choice of atmospheric surface fluxes: A2 versus A2-F}

The differences of atmospheric forcings between A2 and A2-F are substantial. For the 2070-2099 period compared to their respective historical period 1961-1990, the decrease of the net heat loss and increase in E-P water loss are larger in A2-F with $+2.5 \mathrm{~W} \mathrm{~m}^{-2}$ and $+0.73 \mathrm{~mm} \mathrm{~d}^{-1}$ compared to $+2 \mathrm{~W} \mathrm{~m}^{-2}$ and $+0.40 \mathrm{~mm} \mathrm{~d}^{-1}$ in A2. The heat and salt contents of the full water column do not increase similarly in A2 and A2-F: despite the larger E-P and heat fluxes anomalies in A2-F, the propagation of the salt anomalies in the deepest layer $600 \mathrm{~m}$-bottom is larger in A2 (+0.31) than in A2-F $(+0.26)$. As mentioned in Sect. 4.2.4, this happens because this simulation starts from a very convective initial state, and the surface anomalies strongly propagate already at the beginning of the A2 simulation, before the weakening of the MTHC.

Table 7 shows quite different state of the MLD compared to the historical period between A2 and A2-F. In A2, the maximum of the winter MLD, considered as a qualitative proxy for deep water convection, mainly decreases (except in the Aegean). In A2-F, the maximum of winter MLD increases in the eastern basin and decreases in the western basin. As stated in 4.2.3., the MTHC weakens basinwide in $\mathrm{A} 2$, whereas it increases in the eastern basin in A2-F. A2 does not face an EMT-like situation as A2-F but maintains a standard circulation with ADW as main source of eastern dense water, the ADW cell is weaker though (Figs. 5, 6). The warming signal of the deep layer 600-bottom is slightly larger in A2-F than if A2 despite a weaker transfer toward depth (Table 4), this is explained by a much larger surface signal in A2-F than in A2.

\subsubsection{Choice of rivers: A2-F versus A2-RF}

The differences of river forcing between A2-F and A2-RF come from the use of different versions of the ARCM
(RCM3 and RCM4) to obtain the runoff. The impact of the choice of river runoff on the oceanic state of the Mediterranean is negligible. For the 2070-2099 period, the total amount of runoff is decreased by $45 \%$ in A2-F and by $42 \%$ in A2-RF. This difference is mainly due to changes in the fresh water input from the Black Sea (treated as a runoff), which drops from $8,709 \mathrm{~m}^{3} \mathrm{~s}^{-1}$ for the 1961-1990 period to $3,340 \mathrm{~m}^{3} \mathrm{~s}^{-1}$ in $\mathrm{A} 2-\mathrm{F}$ and $3,695 \mathrm{~m}^{3} \mathrm{~s}^{-1}$ in A2-RF (2070-2099). This leads to mean SSS differences of 0.05 between A2-F and A2-RF. The 3D-circulation of the Mediterranean simulated for the future is similar between both simulations (Figs. 5, 6 and 7). Because A2-RF has larger runoff, the vertical stratification is greater than in A2-F, thus the surface heat anomalies do not penetrate as deep as in A2-F. This explains that the 3D averaged temperature anomaly in A2-RF $\left(+0.93{ }^{\circ} \mathrm{C}\right)$ is lower than in A2-F $\left(+1.04^{\circ} \mathrm{C}\right)$ as seen in Table 4 .

\subsubsection{Choice of the Atlantic hydrography: A2-RF versus A2-ARF}

The impact of the hydrographic properties of the Atlantic water on the oceanic state of the Mediterranean is assessed through the comparison of the simulations A2-ARF and A2-RF, whose Atlantic hydrographic conditions come from different GCM versions, GCM2 and GCM3 respectively. Figure 21 displays the anomalies of the Atlantic hydrographic properties in both simulations. Future Atlantic waters which enter in the Mediterranean basin are warmer and saltier than in the historical period. This signal is nevertheless larger in A2-ARF which displays a warming and saltening respectively $0.5{ }^{\circ} \mathrm{C}$ and 0.40 larger than in A2-RF for the 0-150 m layer of Atlantic waters for 2070-2099. This results in a smaller density decrease in A2-ARF (about $-0.1 \mathrm{~kg} \mathrm{~m}^{-3}$ ) than in A2-RF (about $-0.25 \mathrm{~kg} \mathrm{~m}^{-3}$ ), considering the same ocean layer $(0-150 \mathrm{~m})$ and the same time period (2070-2099 vs. 1961-1990). The hydrographic changes of the Atlantic buffer zone are advected through the Mediterranean, which displays mean SSS changes of +0.89 in A2-ARF and +0.64 in A2-RF for 2070-2099 (Table 4).

Table 7 Monthly maximum of the mixed layer depth (in m) and correponding month of occurence. Anomalies (2070-2099 vs. 1961-1990) are represented for the scenario simulations

\begin{tabular}{|c|c|c|c|c|c|}
\hline Experiment or dataset & Gulf of Lions & Adriatic & Levantine & Aegean & North Aegean \\
\hline HIS (1961-1990) & 1,000 (February) & 570 (February) & 660 (March) & 165 (February) & 460 (March) \\
\hline HIS-F (1961-1990) & 400 (January/February) & 440 (February) & 300 (March) & 180 (January) & 350 (March) \\
\hline A2 (2070-2099) & -820 (March) & -120 (March) & -320 (March) & +145 (March) & 0 (March) \\
\hline A2-F (2070-2099) & -200 (February) & +40 (February) & +220 (February) & +100 (February) & +80 (February) \\
\hline A2-RF (2070-2099) & -250 (February) & +40 (February) & +160 (February) & +35 (February) & +30 (February) \\
\hline A2-ARF (2070-2099) & -70 (February) & -90 (February) & +320 (February) & +35 (February) & +10 (February) \\
\hline
\end{tabular}




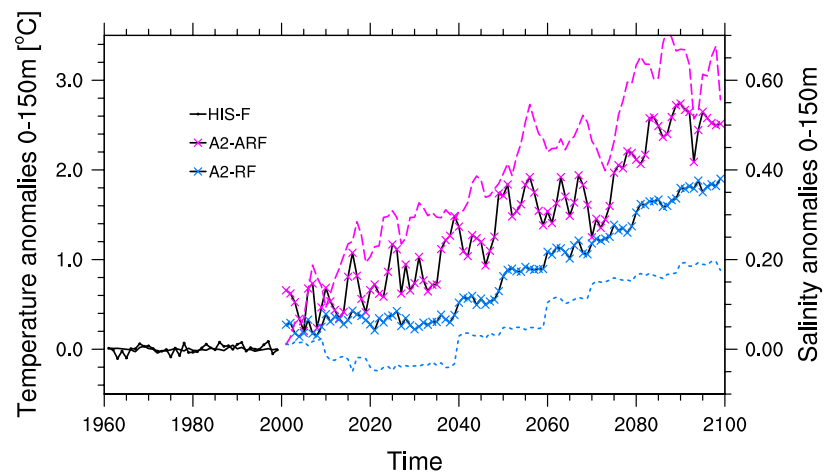

Fig. 21 Time series of temperature (full lines) and salinity (dashed lines) averaged in the Atlantic buffer zone of the model over the upper part of the water column $(0-150 \mathrm{~m})$. Anomalies versus the 1961-1990 period of the HIS simulation are represented

A2-RF and A2-ARF display quite different vertical circulation changes in the eastern Mediterranean. A2-ARF projects a more intense EMT situation for the future than A2-RF (Figs. 5, 18) because A2-RF has a larger surface density decrease from the incoming Atlantic water, thus a stronger vertical stratification than A2-ARF (Fig. 16). For the same reasons, the meridional overturning stream function of the Adriatic basin displays a deeper cascading of the ADW into the north Ionian in A2-ARF than in A2-RF (Fig. 6 ) and the reduction of dense water production in the Gulf of Lions is quite larger in A2-RF (Table 7; Fig. 19). This leads to large differences in the propagation of warming from the surface toward depth. For the same surface warming anomaly of $2.97{ }^{\circ} \mathrm{C}, \mathrm{A} 2$-ARF has a more active transfer than $\mathrm{A} 2-\mathrm{RF}$, as displayed by the heat content anomalies in the $600 \mathrm{~m}$-bottom layer with the values of $+1.14{ }^{\circ} \mathrm{C}$ for A2-ARF versus $+0.68^{\circ} \mathrm{C}$ in A2-RF (Table 4).

The hydrography of the Atlantic water is thus substantially impacting the new organization of water masses production. The changes are weaker in A2-RF whose lower surface density allows a stronger vertical stratification than in the simulation A2-ARF.

\subsection{Sensitivity to the socio-economic scenario}

The comparison between the simulations A2-ARF, A1BARF and B1-ARF provides some answers on the sensitivity to the choice of the socio-economic scenario. Table 4 shows that the surface salinity and temperature changes averaged over the Mediterranean basin are larger in A2-ARF than in A1B-ARF and B1-ARF, consistently with the greenhouse gases concentrations in each scenario. However, both heat and salt content changes over the full water column are found to be larger in A1B-ARF than in A2-ARF, reflecting a larger propagation of the surface heat anomaly to deeper layers in A1B-ARF. A1B-ARF is indeed having the strongest EMT-index among the whole family of scenario simulations (Fig. 18) but also keeps a deep cascading of ADW (Figs. 6, 18) and its maximum of MLD in the Gulf of Lion is not decreasing (unlike A2-ARF). All these features make that the simulation A1B reproduces the strongest vertical circulation at the end of the twenty-first century (Fig. 5), inducing thus the strongest advection of the surface changes toward deep layers. B1-ARF, as the moderate scenario, displays the weakest surface hydrographic changes, and the largest decrease of vertical stratification compared to its historical period. It shows a small increase of the dense water formation in the Gulf of Lions (Fig. 19), its EMT signal is the weakest among the 3 scenarios, and it maintains a strong ADW formation with an intense cell and a deep cascading into the Ionian basin (Figs. 5, 6).

\subsection{Impact of the socio-economic scenario} versus boundary conditions

With this large family of scenario simulations, we were able to identify to what extent the choice of the boundary conditions and socio-economic scenario impacts the oceanic changes in the future Mediterranean. The results are found to be especially sensitive to the choice of the Atlantic forcing and the socio-economic scenario. Depending on the prescribed Atlantic hydrography, the ocean model faces a vertical stratification which can modulate the response of the water masses dynamics with more or less dense water formation. The propagation of the heat from the surface through the depth is thus affected and a different response of the Mediterranean thermosteric sea level is expected (Fig. 20). From our qualitative analysis, we infer that the sensitivity to the choice of the Atlantic boundary conditions is at least of the same order as the sensitivity to the choice of the socio-economic scenario, if not larger. In Table 8, we quantify these differences by comparing the spread between the 3 simulations where only the socio-economic scenario differs (A2-ARF, A1B-ARF and B1-ARF), called $\Delta$ Scen, with the spread between the 2 simulations with different Atlantic conditions only (A2-ARF and A2-RF), called $\Delta$ Atl. For the heat and salt contents of the full water column averaged over the 2070-2099 period, $\Delta$ Atl is larger with a spread of +0.16 and $+0.30{ }^{\circ} \mathrm{C}$ against +0.09 and +0.24 ${ }^{\circ} \mathrm{C}$ for $\Delta \mathrm{Scen}$. The difference between $\Delta \mathrm{Atl}$ and $\Delta \mathrm{Scen}$ increases for the deepest layer with a spread of +0.19 and $+0.46{ }^{\circ} \mathrm{C}$ for $\Delta \mathrm{Atl}$ against +0.10 and $+0.26{ }^{\circ} \mathrm{C}$ for $\Delta$ Scen. The spreads for the two other boundary forcings, rivers ( $\Delta$ Riv) and atmospheric fluxes $(\Delta \mathrm{Atm})$, are much smaller than $\Delta$ Atl and $\Delta$ Scen. Table 8 also compares the different spreads of the EMT-index and confirms that the sensitivity to the Atlantic forcing is the largest.

Concerning the changes in thermosteric mean sea level for the 2070-2099 period (Fig. 20), $\Delta$ Atl displays a spread 
Table 8 Sensitivity of different quantities to the following forcings: atmospheric fluxes $(\Delta \mathrm{Atm})$, river runoff ( $\Delta$ Riv), Atlantic hydrography ( $\Delta \mathrm{Atl})$ and socio-economic scenario $(\Delta \mathrm{Scen})$. The values are computed over the 2070-2099 period

\begin{tabular}{lllll}
\hline & $\Delta$ Atm & $\Delta$ Riv & $\Delta$ Atl & $\Delta$ Scen \\
\hline SST $\left({ }^{\circ} \mathrm{C}\right)$ & 0.45 & 0 & 0 & 1.24 \\
SSS & 0.21 & 0.05 & 0.25 & 0.19 \\
T0-bot $\left({ }^{\circ} \mathrm{C}\right)$ & 0.07 & 0.11 & 0.30 & 0.26 \\
S0-bot & 0 & 0.05 & 0.16 & 0.09 \\
T600-bot $\left({ }^{\circ} \mathrm{C}\right)$ & 0.03 & 0.11 & 0.46 & 0.24 \\
S600-bot & 0.05 & 0.04 & 0.19 & 0.10 \\
Thermosteric SL $(\mathrm{cm})$ & 3 & 4 & 11 & 9 \\
EMT-index (Sv) & 1.01 & 0 & 1.21 & 0.89 \\
\hline
\end{tabular}

of $11 \mathrm{~cm}$, with an increase between 34 and $45 \mathrm{~cm}$. This large difference is driven by a weaker penetration of the heat anomaly in the A2-RF simulation, due to a weaker eastern convection compared to A2-ARF. $\triangle$ Scen has a spread of $9 \mathrm{~cm}$ with a range between 40 and $49 \mathrm{~cm}$. $\Delta$ Riv and $\Delta \mathrm{Atm}$ show respectively a spread of 4 and $3 \mathrm{~cm}$.

This results highlight the relevance of the choice of boundary conditions for Mediterranean ocean projections. The choice of Atlantic conditions seems to be of highest importance and prevails on the choice of the socio-economic scenario.

\subsection{Discussion on uncertainties among other models}

In order to place our results in a wider context, we compare the uncertainty ranges explored in our study for each of the three boundary conditions with the large spread among global and/or regional models. From the study by Marcos and Tsimplis (2008), 10 GCMs used in CMIP3 show a large spread of changes in Atlantic hydrography computed for the buffer zone of NEMOMED8 model for the layer $0-150 \mathrm{~m}$. The changes vary from -0.35 to +0.66 for salinity, and from -0.06 to $+2.56{ }^{\circ} \mathrm{C}$ for temperature. This gives a range of 1.01 in salinity and $2.62{ }^{\circ} \mathrm{C}$ in temperature, which is larger than the uncertainty range used in our study ( 0.40 for salinity and $0.5{ }^{\circ} \mathrm{C}$ for temperature). SanchezGomez et al. (2009) analysed Mediterranean runoff changes for the 2070-2099 period among various regional climate models and found a runoff decrease ranging from -5 to $-43 \%$, and changes in Black Sea fresh water input from +25 to $-102 \%$. In our study, the uncertainty ranges from -5 to $-32 \%$ for rivers and -25 to $-61 \%$ for the Black Sea input, thus is smaller than the "possible" range of uncertainty. For the total fresh water budget, SanchezGomez et al. (2009) found changes from +20 to $+60 \%$ whereas our study investigates changes from +35 to $+60 \%$. Finally, the study by Dubois et al. (2012) compiles model data from the CIRCE project with net heat budget changes ranging from +2 to $+5.5 \mathrm{~W} \mathrm{~m}^{-2}$. In our study we propose a smaller range of uncertainty which is between +1 to $+3 \mathrm{~W} \mathrm{~m}^{-2}$. The uncertainty range explored in our study is about 2-3 times smaller than the spread displayed among other regional and global models regarding the projected changes in Atlantic hydrography, river runoffs and atmospheric fluxes. Therefore, the spread of our ensemble must be considered as a lower bound for the actual range of uncertainties in Mediterranean Sea projections.

\section{Conclusions and perspectives}

To our knowledge, this study is the first attempt to assess the sensitivity of the Mediterranean response to various uncertainties in a context of climate change scenario.

We performed a 6-member ensemble of scenario sensitivity simulations, which allows to analyse the sensitivity to three types of boundary forcings (rivers, atmospheric fluxes and Atlantic hydrography) as well as the sensitivity related to the choice of the socio-economic scenario. We found that the mean Mediterranean SST and SSS are increasing with a range between +1.73 and $+2.97{ }^{\circ} \mathrm{C}$, and +0.48 and +0.89 for the period 2070-2099 compared to 1961-1990. The propagation of these surface anomalies leads to an increase of heat and salt contents of the full water column with a spread between +0.93 to $+1.35{ }^{\circ} \mathrm{C}$ for the global averaged temperature and between +0.28 to +0.52 for the global averaged salinity. Results have shown that the future MTHC tends to face an EMT-like situation in most of the cases, with the Aegean Sea becoming the main source of eastern Mediterranean dense water. We also found that this response is strongly modulated by the chosen boundary conditions and socio-economic scenario. The Atlantic forcing has the largest effect on the long-term future evolution of the MTHC, followed by the socio-economic scenario. Both atmospheric fluxes and rivers show a much smaller impact. The transfer of the surface anomalies toward depth does not only depend on the MTHC changes in the future but also on the historical state of the vertical stratification of the basin and the associated MTHC. A weak stratification and active MTHC during the historical period drive a quick penetration of the surface warming and saltening already at the beginning of the scenario simulation, as shown for A2. Besides, the activation of an EMT-circulation modelled in most of the scenario simulations leads to the propagation of the large anomalies in the deep layers of the eastern Mediterranean. The MTHC in the western basin generally tends to decrease, confirming the results of Somot et al. (2006). Large changes in subsurface circulation are also simulated for the end of the twenty-first century, especially in the Balearic and Ionian regions. Finally, the response of 
thermosteric sea level ranges from +34 to $+49 \mathrm{~cm}$, mainly depending on the Atlantic forcing.

This study points out the relevance of a good representation of the Atlantic conditions in Mediterranean ocean models. We only considered two different versions of a same GCM but we can expect much larger differences of the Mediterranean response knowing that some GCMs project a decrease of the salinity in the nearby Atlantic. There is also a need to evaluate the strength of the MTHC in present climate to better estimate and understand its change in the future. Not assessed in this study, another source of uncertainty is the choice of the ocean model. This aspect will be investigated within the ongoing model-intercomparison project Med-CORDEX (www.medcordex.eu). Finally, our results could be useful to evaluate the impact of climate change on Mediterranean marine biogeochemistry and ecosystems.

Acknowledgments This study was carried out in the frame of a post-doc project funded by AXA Research Fund. We thank Loïc Houpert for providing the climatology of mixed layer depth. Most of the simulations were carried in the framework of the projects VANIMEDAT-2 (CTM2009-10163-C02-01, funded by the Spanish Marine Science and Technology Program and the E-Plan of the Spanish Government) and ESCENARIOS (funded by the Agencia Estatal de METeorología, AEMET). This work is also a contribution to the HyMeX programme (HYdrological cycle in the Mediterranean EXperiment) through INSU-MISTRALS support and the Med-CORDEX initiative (http://www.medcordex.eu/). This research has received funding from the French National Research Agency (ANR) project REMEMBER (contract ANR-12-SENV-001). We also thank the european projects FP7 CLIM-RUN (contract FP7ENV-2010-265192) and FP7-IMPACT2C (grant 282746) for their support. G. Jordà acknowledges a "Ramón y Cajal" contract funded by the Spanish Government (RYC-2013-14714) and a postdoctoral grant from the Conselleria d'Educacio, Cultura i Universitats del Govern de les Illes Balears and the European Science Foundation. Finally, we thank both reviewers for their helpful comments to improve the manuscript.

Open Access This article is distributed under the terms of the Creative Commons Attribution License which permits any use, distribution, and reproduction in any medium, provided the original author(s) and the source are credited.

\section{References}

Adloff F, Mikolajewicz U, Kucera M, Grimm R, Maier-Reimer E, Schmiedl G, Emeis K (2011) Upper ocean climate of the Eastern Mediterranean Sea during the Holocene Insolation Maximum-a model study. Clim. Past 7:1103-1122. doi:10.5194/ cp-7-1103-2011

Arakawa A, Lamb VR (1977) Computational design of the basic dynamical processes of the UCLA general circulation model. Methods Comput Phys 17:173-265

Beuvier J, Sevault F, Herrmann M, Kontoyiannis H, Ludwig W, Rixen M, Stanev E, Béranger K, Somot S (2010) Modeling the Mediterranean Sea interannual variability during 1961-2000: focus on the Eastern Mediterranean transient. J Geophys Res Oceans 115:C08,017. doi:10.1029/2009JC005950
Carillo A, Sannino G, Artale V, Ruti PM, Calmanti S, Dell'Aquila A (2012) Steric sea level rise over the Mediterranean Sea: present climate and scenario simulations. Clim Dyn 39(9-10):21672184. doi:10.1007/s00382-012-1369-1

Christensen JH, Carter TR, Rummukainen M, Amanatidis G (2007) Evaluating the performance and utility of regional climate models: the PRUDENCE project. Clim Change 81:1-6. doi:10.1007/ s10584-006-9211-6

Déqué M (2007) Frequency of precipitation and temperature extremes over France in an anthropogenic scenario: model results and statistical correction according to observed values. Global Planet Change 57(1-2):16-26. doi:10.1016/j.gloplacha.2006.11.030

Déqué M, Piedelièvre J (1995) High-resolution climate simulation over Europe. Clim Dyn 11:321-339

Déqué M, Dreveton C, Braun A, Cariolle D (1994) The ARPEGE-IFS atmosphere model: a contribution to the French community climate modelling. Clim Dyn 10:249-266

Dubois C, Somot S, Calmanti S, Carillo A, Déqué M, Dell'Aquilla A, Elizalde A, Gualdi S, Jacob D, L'Hévéder B, Li L, Oddo P, Sannino G, Scoccimarro E, Sevault F (2012) Future projections of the surface heat and water budgets of the Mediterranean Sea in an ensemble of coupled atmosphere-ocean regional climate models. Clim Dyn 39(7-8):1859-1884. doi:10.1007/ s00382-011-1261-4

Elguindi N, Somot S, Déqué M, Ludwig W (2011) Climate change evolution of the hydrological balance of the Mediterranean, Black and Caspian Seas: impact of climate model resolution. Clim Dyn 36(1-2):205-228. doi:10.1007/s00382-009-0715-4

Gibelin AL, Déqué M (2003) Anthropogenic climate change over the Mediterranean region simulated by a global variable resolution model. Clim Dyn 20:327-339

Giorgi F (2006) Climate change hot-spots. Geophys Res Lett 33(8):L08,707

Gualdi S, Somot S, Li L, Artale V, Adani M, Bellucci A, Braun A, Calmanti S, Carillo A, Dell'Aquila A, Déqué M, Dubois C, Elizalde A, Harzallah A, Jacob D, L'Hévéder B, May W, Oddo P, Ruti P, Sanna A, Sannino G, Scoccimarro E, Sevault F, Navarra A (2013) The CIRCE simulations regional climate change projections with realistic representation of the Mediterranean Sea. Bull Am Meteorol Soc 94(1):65-81. doi:10.1175/BAMS-D-11-00136.1

Harzallah A, Cadet DL, Crépon M (1993) Possible forcing effects of net evaporation, atmospheric-pressure, and transients on water transports in the Mediterranean Sea. J Geophys Res Oceans 98(C7):12,341-12,350. doi:10.1029/93JC00376

Herrmann M, Estournel C, Déqué M, Marsaleix P, Sevault F, Somot S (2008a) Dense water formation in the Gulf of Lions shelf: impact of atmospheric interannual variability and climate change. Cont Shelf Res 28(15):2092-2112

Herrmann M, Somot S, Sevault F, Estournel C, Déqué M (2008b) Modeling the deep convection in the northwestern Mediterranean Sea using an eddy-permitting and an eddy-resolving model: case study of winter 1986-1987. J Geophys Res Oceans 113(C4):C04,011. doi:10.1029/2006JC003991

Herrmann M, Sevault F, Beuvier J, Somot S (2010) What induced the exceptional 2005 convection event in the northwestern Mediterranean basin? Answers from a modeling study. J Geophys Res Oceans 115:C12,051. doi:10.1029/2010JC006162

Herrmann M, Estournel C, Adloff F, Diaz F (2014) Impact of climate change on the northwestern Mediterranean Sea pelagic planktonic ecosystem and associated carbon cycle. J Geophys Res Oceans 119(9):5815-5836. doi:10.1002/2014JC010016

Houpert L, Testor P, Durrieu de Madron X, Somot S, D'Ortenzio F, Estournel C, Lavigne H (2014) Observations of the mixed layer, the seasonal thermocline and the upper-ocean heat storage rate to estimate the seasonal cycle of the net heat flux over the Mediterranean Sea. Prog Oceanogr. doi:10.1016/j.pocean.2014.11.004 
Ingleby B, Huddleston M (2007) Quality control of ocean temperature and salinity profiles-historical and real-time data. J Mar Syst 65(1-4):158-175. doi:10.1016/j.jmarsys.2005.11.019

IPCC (2007) Climate change 2007: the physical science basis. Contribution of working group I to the fourth assessment report of the intergovernmental panel on climate change. Cambridge University Press, Cambridge

IPCC (2013) Climate change 2013: the physical science basis. Working group I contribution to the fifth assessment report of the intergovernmental panel on climate change. Cambridge University Press, Cambridge

Klein B, Roether W, Manca B, Bregant D, Beitzel V, Kovacevic V, Luchetta A (1999) The large deep water transient in the Eastern Mediterranean. Deep-Sea Res Part I 46:371-414

Kourafalou VH, Barbopoulos K (2003) High resolution simulations on the North Aegean Sea seasonal circulation. Annal Geophys 21(1):251-265

Lacombe H, Tchernia P (1972) Caractère hydrologique et circulation de eaux en Méditerranée. In: Stanley DJ (ed) The Mediterranean Sea Dowden, Hutchinson, and Ross, Stroudsburg, PA. pp 26-36

Lascaratos A (1993) Estimation of deep and intermediate water mass formation rates in the Mediterranean Sea. Deep-Sea Res Part II Top Stud Oceanogr 40(6): 1327-1332

Lascaratos A, Roether W, Nittis K, Klein B (1999) Recent changes in deep water formation and spreading in the eastern Mediterranean Sea: a review. Prog Oceanogr 44(1-3):5-36. doi:10.1016/ S0079-6611(99)00019-1

Lazzari P, Mattia G, Solidoro C, Salon S, Crise A, Zavatarelli M, Oddo P, Vichi M (2013) The impacts of climate change and environmental management policies on the trophic regimes in the Mediterranean Sea: Scenario analyses. J Mar Syst. doi:10.1016/j. jmarsys.2013.06.005. http://www.sciencedirect.com/science/ article/pii/S0924796313001425

Li L, Bozec A, Somot S, Béranger K, Bouruet-Aubertot P, Sevault F, Crépon M (2006) Regional atmospheric, marine processes and climate modelling (chapter 7). In: Lionello P, Malanotte P, Boscolo R (eds) Mediterranean climate variability. Elsevier B.V, Amsterdam, pp 373-397

Li L, Casado A, Dell'Aquila A, Dubois C, Elizalde A, L'Hévéder B, Lionello P, Sevault F, Somot S, Ruti P, Zampieri M (2011) Modelling of the Mediterranean climate system (chapter 7). In: Lionello P (ed) Mediterranean Climate Variability. Elsevier B.V., Amsterdam, pp 419-448

Ludwig W, Dumont E, Meybeck M, Heussner S (2009) River discharges of water and nutrients to the Mediterranean and Black Sea: major drivers for ecosystem changes during past and future decades? Prog Oceanogr 80(3-4):199-217

Madec G (2008) NEMO ocean engine. IPSL/LODYC, Paris, France, note du Pôle de modélisation $\mathrm{n}^{\circ} 27$

Madec G, Delecluse P, Imbard M, Levy C (1998) OPA 8.1, ocean general circulation model, reference manual. IPSL/LODYC, Paris, France, note du Pôle de modélisation $\mathrm{n}^{\circ} 11$

Malanotte-Rizzoli P, Artale V, Borzelli-Eusebi GL, Brenner S, Crise A, Gacic M, Kress N, Marullo S, Ribera d'Alcalà M, Sofianos S, Tanhua T, Theocharis A, Alvarez M, Ashkenazy Y, Bergamasco A, Cardin V, Carniel S, Civitarese G, D’Ortenzio F, Font J, GarciaLadona E, Garcia-Lafuente JM, Gogou A, Gregoire M, Hainbucher D, Kontoyannis H, Kovacevic V, Kraskapoulou E, Kroskos G, Incarbona A, Mazzocchi MG, Orlic M, Ozsoy E, Pascual A, Poulain PM, Roether W, Rubino A, Schroeder K, Siokou-Frangou J, Souvermezoglou E, Sprovieri M, Tintoré J, Triantafyllou G (2014) Physical forcing and physical/biochemical variability of the Mediterranean Sea: a review of unresolved issues and directions for future research. Ocean Sci 10(3):281-322. doi:10.5194/ os-10-281-2014. http://www.ocean-sci.net/10/281/2014/
Marcos M, Tsimplis MN (2008) Comparison of results of AOGCMs in the Mediterranean Sea during the 21st century. J Geophys Res Oceans 113(C12):C12,028

Mariotti A, Zeng N, Yoon JH, Artale V, Navarra A, Alpert P, Li LZX (2008) Mediterranean water cycle changes: transition to drier 21st century conditions in observations and CMIP3 simulations. Environ Res Lett 3(4):044,001. doi:10.1088/1748-9326/3/4/044001

Marullo S, Artale V, Santoleri R (2011) The SST multidecadal variability in the Atlantic-Mediterranean region and its relation to AMO. J Clim 24(16):4385-4401. doi:10.1175/2011JCLI3884.1

Matthiesen S, Haines K (2003) A hydraulic box model study of the Mediterranean response to postglacial sea-level rise. Paleoceanography 18(4):1084

MEDAR-Group (2002) Medatlas 2002 database, cruise inventory, observed and analyzed data of temperature and bio-chemical parameters. IFREMER Edition (4 CDRom)

Millot C, Taupier-Letage I (2005) Circulation in the Mediterranean Sea. In: The handbook of environmental chemistry, vol 5: water pollution, Part K. Springer, Berlin, pp 29-66. doi:10.1007/ b107143

Myers PG, Haines K (2002) Stability of the Mediterranean's thermohaline circulation under modified surface evaporative fluxes. J Geophys Res 107(C3):7-1-10

Naranjo C, Garcia-Lafuente J, Sannino G, Sanchez-Garrido JC (2014) How much do tides affect the circulation of the Mediterranean Sea? From local processes in the Strait of Gibraltar to basin-scale effects. Prog Oceanogr 127:108-116. doi:10.1016/j. pocean.2014.06.005

Oddo P, Adani M, Pinardi N, Fratianni C, Tonani M, Pettenuzzo D (2009) A nested Atlantic-Mediterranean Sea general circulation model for operational forecasting. Ocean Sci 5(4):461-473

Pettenuzzo D, Large WG, Pinardi N (2010) On the corrections of ERA-40 surface flux products consistent with the Mediterranean heat and water budgets and the connection between basin surface total heat flux and NAO. J Geophys Res Oceans 115:C06,022. doi:10.1029/2009JC005631

Pinardi N, Zavatarelli M, Adani M, Coppini G, Fratianni C, Oddo P, Simoncelli S, Tonani M, Lyubartsev V, Dobricic S, Bonaduce A (2013) Mediterranean Sea large-scale low-frequency ocean variability and water mass formation rates from 1987 to 2007: a retrospective analysis. Prog Oceanogr. doi:10.1016/j. pocean.2013.11.003. http://www.sciencedirect.com/science/ article/pii/S007966111300222X

Planton S, Lionello P, Artale V, Aznar R, Carillo A, Colin J, Congedi L, Dubois C, Elizalde A, Gualdi S, Hertig E, Jacobeit J, Jorda G, Li L, Mariotti A, Piani C, Ruti P, Sanchez-Gomez E, Sannino G, Sevault F, Somot S, Tsimplis M (2012) Modelling of the Mediterranean climate system (chapter 8). In: Lionello P (ed) Mediterranean climate variability. Elsevier B.V., Amsterdam, pp 449-502

Reynaud T, Legrand P, Mercier H, Barnier B (1998) A new analysis of hydrographic data in the Atlantic and its application to an inverse modeling study. Int WOCE Newslett 32:29-31

Roether W, Manca BB, Klein B, Bregant D, Georgopoulos D, Beitzel V, Kovacevic V, Luchetta A (1996) Recent changes in eastern Mediterranean deep waters. Science 271(5247):333-335. doi: $10.1126 /$ science. 271.5247 .333

Roether W, Klein B, Manca BB, Theocharis A, Kioroglou S (2007) Transient Eastern Mediterranean deep waters in response to the massive dense-water output of the Aegean Sea in the 1990s. Prog Oceanogr 74(4):540-571. doi:10.1016/j.pocean.2007.001

Rohling EJ (1991) Shoaling of the eastern Mediterranean pycnocline due to reduction of excess evaporation: implications for sapropel formation. Paleoceanography 6(6):747-53

Rohling EJ (1994) Review and new aspects concerning the formation of eastern Mediterranean sapropels. Mar Geol 122(1-2):1-28 
Royer JF, Cariolle D, Chauvin F, Déqué M, Douville H, Planton S, Rascol A, Ricard JL, Salas y Mélia D, Sevault F, Simon P, Somot S, Tyteca S, Terray L, Valcke S (2002) Simulation of climate changes during the 21st century including stratospheric ozone. Géosciences 334(3):147-154. doi:10.1016/S1631-0713(02)01728-5

Salas y Mélia D, Chauvin F, M D, Douville H, Guérémy J, Marquet P, Planton S, Royer J, Tyteca S (2005) Description and validation of CNRM-CM3 global coupled climate model, Note de Centre du GMGEC N ${ }^{\circ} 103$. Technical report

Sanchez-Gomez E, Somot S, Mariotti A (2009) Future changes in the Mediterranean water budget projected by an ensemble of regional climate models. Geophys Res Lett 36:L21,401. doi:10.1029/200 9GL040120

Sanchez-Gomez E, Somot S, Josey SA, Dubois C, Elguindi N, Déqué M (2011) Evaluation of Mediterranean Sea water and heat budgets simulated by an ensemble of high resolution regional climate models. Clim Dyn 37(9-10):2067-2086. doi:10.1007/ s00382-011-1012-6

Sannino G, Sanchez-Garrido JC, Liberti L, Pratt L (2014) Exchange flow through the strait of gibraltar as simulated by a -coordinate hydrostatic model and a z-coordinate nonhydrostatic model (chapter 3) In: Borzelli GL, Gacic M, Lionello P, Malanotte-Rizzoli $\mathrm{P}$ (eds) The Mediterranean Sea: temporal variability and spatial patterns, 04/2014. AGU Book-Wiley, New York, pp 25-50. ISBN: 978-1-118-84734-3

Sannino G, Pratt L, Carillo A (2009) Hydraulic criticality of the exchange flow through the strait of gibraltar. J Phys Oceanogr 39(11):2779-2799. doi:10.1175/2009JPO4075.1

Sevault F, Somot S, Beuvier J (2009) A regional version of the NEMO ocean engine on the Mediterranean Sea: NEMOMED8 user's guide. Note de centre du GMGEC ${ }^{\circ} 107$. Technical report

Skliris N, Lascaratos A (2004) Impacts of the Nile River damming on the thermohaline circulation and water mass characteristics of the Mediterranean Sea. J Mar Syst 52(1-4):121-143. doi:10.1016/j. jmarsys.2004.02.005

Skliris N, Sofianos S, Lascaratos A (2007) Hydrological changes in the Mediterranean Sea in relation to changes in the freshwater budget: a numerical modelling study. J Mar Syst 65(1-4):400416. doi:10.1016/j.jmarsys.2006.01.015

Somot S (2005) Modélisation climatique du bassin méditerranéen: variabilité et scénarios de changement climatique. $\mathrm{PhD}$ thesis, Université de Toulouse III

Somot S, Sevault F, Déqué M (2006) Transient climate change scenario simulation of the Mediterranean Sea for the twenty-first century using a high-resolution ocean circulation model. Clim Dyn 27(7-8):851-879
Soto-Navarro J, Criado-Aldeanueva F, Garcia-Lafuente J (2010) Estimation of the Atlantic inflow through the Strait of Gibraltar from climatological and in situ data. J Geophys Res Oceans 115:C10,023. doi:10.1029/2010JC006302

Soto-Navarro J, Somot S, Sevault F, Beuvier J, Criado-Aldeanueva F, Garca-Lafuente J, Béranger K (2014) Evaluation of regional ocean circulation models for the Mediterranean Sea at the Strait of Gibraltar: volume transport and thermohaline properties of the outflow. Clim Dyn 1-16. doi:10.1007/s00382-014-2179-4

Stanev EV, Le Traon PY, Peneva EL (2000) Sea level variations and their dependency on meteorological and hydrological forcing: analysis of altimeter and surface data for the Black Sea. J Geophys Res Oceans 105(C7):17,203-17,216

Struglia MV, Mariotti A, Filograsso A (2004) River discharge into the Mediterranean Sea: climatology and aspects of the observed variability. J Clim 17(24):4740-4751. doi:10.1175/JCLI-3225.1

Theocharis A, Nittis K, Kontoyiannis H, Papageorgiou E, Balopoulos E (1999) Climatic changes in the Aegean Sea influence the Eastern Mediterranean thermohaline circulation (1986-1997). Geophys Res Lett 26(11):1617-1620

Thorpe RB, Bigg GR (2000) Modelling the sensitivity of Mediterranean Outflow to anthropogenically forced climate change. Clim Dyn 16(5):355-368. doi:10.1007/s003820050333

Tsimplis M, Marcos M, Somot S, Barnier B (2008) Sea level forcing in the Mediterranean Sea between 1960 and 2000. Global Planet Change 63(4):325-332

Uppala SM, Kallberg PW, Simmons AJ, Andrae U, Bechtold VD, Fiorino M, Gibson JK, Haseler J, Hernandez A, Kelly GA, Li X, Onogi K, Saarinen S, Sokka N, Allan RP, Andersson E, Arpe K, Balmaseda MA, Beljaars ACM, Van De Berg L, Bidlot J, Bormann N, Caires S, Chevallier F, Dethof A, Dragosavac M, Fisher M, Fuentes M, Hagemann S, Holm E, Hoskins BJ, Isaksen L, Janssen PAEM, Jenne R, McNally AP, Mahfouf JF, Morcrette JJ, Rayner NA, Saunders RW, Simon P, Sterl A, Trenberth KE, Untch A, Vasiljevic D, Viterbo P, Woollen J (2005) The ERA-40 re-analysis. Quart J R Meteorol Soc 131(612):2961-3012

Valcke S (2013) The OASIS3 coupler: a European climate modelling community software. Geosci Model Dev 6:373-388. doi:10.5194/ gmd-6-373-2013

Vörösmarty C, Fekete B, Tucker B (1998) Global river discharge, 1807-1991, Version. 1.1 RivDIS Data set. http://www.daacornl. gov from Oak Ridge National Laboratory Distributed Active Archive Center, Oak Ridge, TN

Zervakis V, Georgopoulos D, Karageorgis A, Theocharis A (2004) On the response of the Aegean Sea to climatic variability: a review. Int J Climatol 24:1845-1858 